\title{
Uma escola latino-americana de hegemonia? Elementos para uma proposta interpretativa ${ }^{1}$
}

Raúl Burgos ${ }^{2}$

\section{Resumo}

O objetivo deste trabalho é esboçar, de modo descritivo, não analítico, uma paisagem das principais correntes da recepção do conceito gramsciano de hegemonia na América Latina, argumentando que, na diversidade de interpretações envolvidas podemos encontrar características que nos permitem, em termos hipotéticos, falar de uma "escola latino-americana da hegemonia". Neste sentido, é realizada uma exposição geográfica e temática, com o objetivo de evidenciar os contornos mais relevantes dessa "escola". Na última seção do artigo, o autor trava um breve diálogo crítico com a interpretação pós-colonial da recepção de Gramsci na América Latina proposta por Walter Mignolo, e com a abordagem que denomina escola filológica italiana dos estudos gramscianos.

\section{Palavras-chave}

Gramsci; América Latina; Tradutibilidade; Teoria da Hegemonia.

\section{A Latin American school of hegemony? Elements for an interpretive proposal}

\begin{abstract}
The aim of this work is to outline, in a descriptive, non-analytical way, a landscape of the main currents of the Latin America reception of the Gramscian concept of hegemony, arguing that, in the diversity of interpretations involved, we can find characteristics that allow us, in hypothetical terms, to speak of a "Latin American school of hegemony". In this sense, the author proceeds to an exposition, both geographical and thematic, in order to highlight the most relevant characteristics of this "school". In the last section of the article, the author engages in a brief critical dialogue with the post-colonial interpretation of Cramsci's reception in Latin America proposed by Walter Mignolo, and with the approach that he calls the Italian philological school of Gramscian studies.
\end{abstract}

\section{Keywords}

Cramsci; Latin America; Translatability; Theory of Hegemony.

Artigo recebido em junho de 2021

Artigo aceito em junho de 2021 


\section{Introdução}

Uma primeira versão deste texto foi apresentada na ocasião do Seminário Egemonia dopo Gramsci. Una riconsiderazione (4), ocorrida em Urbino, no outubro de 2018. Uma vez que considero esse seminário um verdadeiro laboratório, hoje, como então, este texto continua a representar uma hipótese de trabalho e discussão, e, como tal, se propõe a estimular o debate. Neste sentido, agradeço, de antemão, ao leitor pela paciência e compreensão. Gostaria, por outro lado, de exprimir a minha gratidão, mais uma vez, a Fabio Frosini, guerreiro incansável na realização desses seminários, e aos colegas que continuam, muitas vezes sustentando a participação por conta própria, a alimentar essa discussão.

Na ocasião da reunião do seminário ocorrida em Pavia em 2016, estava convencido de que aquela seria a última vez que estaria me ocupando do tema "Gramsci na América Latina"3. De fato, pretendia expor, na edição de 2018 do seminário, algumas questões teóricas que vinha trabalhando nos últimos anos, e que ainda não havia encontrado oportunidade de discutir publicamente ${ }^{4}$. Todavia, as discussões de Pavia, continuadas posteriormente em Roma, em maio de 2017, em Campinas (Brasil), na reunião conjunta da International Cramsci Society (ICS) internacional e da ICS-Brasil, em agosto de 2017, nos encontros pela refundação da Asociación Gramsci Argentina (2017 e 2018), além das inúmeras conversações com colegas provenientes de diversos países da América Latina, me convenceram de que, na América Latina, se desenvolvera um modo particular de receber e compreender o patrimônio gramsciano, em particular no que se refere à abordagem da teoria da hegemonia. Ou, mais precisamente, que os vários modos como tal herança foi apropriada na América Latina podem ser lidos, de fato, como uma identidade própria, a partir de alguns traços característicos. É essa tradição de leitura - pretendo sugerir neste artigo - que pode ser pensada como "escola latinoamericana da hegemonia", propondo alguns elementos interpretativos sobre sua caracterização, e apenas de modo hipotético. 
Considero que o ponto histórico de maturidade na consolidação da teoria da hegemonia como chave explicativa e projetiva para pensar a América Latina se encontra no cruzamento dos anos 1970 e 1980. Como sustentei em outras ocasiões, um nó central, histórico e simbólico, pode ser encontrado no seminário de Morelia, ocorrido em fevereiro de 1980, intitulado Hegemonía y alternativas políticas en América Latina, em que a teoria da hegemonia, com razões próprias latino-americanas, afirma-se como modelo alternativo de teoria do movimento e da transformação social. A discussão travada em Morelia tivera um antecedente durante o seminário Gramsci y la politica, ocorrido na Cidade do México em 1978, e foi continuada em Oaxaca, em abril de 1981, na ocasião do seminário intitulado Los nuevos procesos sociales y la teoría política contemporánea ${ }^{5}$.

A América Latina saía de um período escuro (ditaduras, doutrina da segurança interna, Operação Condor, exacerbação das políticas neocoloniais norte-americanas etc.) e, entre as várias alternativas de transição - ou seja, as diversas variantes daquela que se tornaria conhecida como teoria da transição democrática -, nessas novas discussões - na Cidade do México (1978), Morelia (1980) e Oaxaca (1981) - se evidenciava uma abordagem alternativa, tanto em relação às teorias de matriz liberal (Guillermo O'Donnell, Carlos Strasser, etc.), bem como em relação à precedentes interpretações da teoria marxista e, finalmente, a outras teorias de caráter "nacional-popular" (entre as quais, o nacionalismo revolucionário, a teologia da libertação, a filosofia da libertação, parte da teoria da dependência). Essa nova abordagem era representada pela teoria da hegemonia, que se desenvolveria crescentemente como resposta teórico-política à crise teórica, ou seja, uma resposta teórica que encontrava a sua fonte na dimensão política.

Veja-se, por exemplo, como Carlos Sirvent, coordenador do seminário Gramsci y la política, explicitava os objetivos do seminário:

Os debates, [...] visam explicar um conjunto de fenômenos políticos que, tanto no México como na América Latina, foram estuda- 
dos à luz de concepções tradicionais e, portanto, era impossível compreender e explicar problemas como o crescimento que teve o aparelho de Estado obtendo cada vez mais o apoio de grandes setores da população; ou seja, não tinha sido possível compreender problemas que são descobertos a partir da concepção gramsciana. Esta conferência implica, portanto, a possibilidade de descobrir se Gramsci é útil para a América Latina ou não, e, para isso, conta com grandes especialistas que fizeram uso de todos os instrumentos gramscianos. (SIRVENT, 1978, p. 10).

O relato de Sirvent é uma excelente manifestação de um movimento teórico que, na conjuntura histórica, estava já em fase de gestação: havia um conjunto de problemas "impossíveis de compreender e explicar", porque tinham sido estudados à luz das concepções tradicionais, e que podiam ser "descobertos" a partir da "teoria gramsciana”.

A viragem gramsciana era, em suma, evidente. Os sucessivos seminários ocorridos em Morelia e Oaxaca, com expressiva participação de especialistas, representariam a fase madura daquela reflexão no território latino-americano. O mesmo apelo à política se encontra, por exemplo, na introdução de José Aricó ao volume que agrupa as intervenções do seminário de Morelia:

O objetivo do seminário era quebrar esse tipo de lacuna/brecha aberta entre a análise da realidade e as propostas teóricas e políticas de transformação. Para isso, era necessário buscar uma aproximação à política que, sem distorcer a natureza de um seminário de cientistas sociais onde se discute sobre teoria política, se esforçasse por encontrar um nível de mediação com a realidade em que as fronteiras demasiado rígidas entre o que o "acadêmico "e o "político" ficassem atenuadas [...]. (ARICÓ, 1985, p. 11-12).

Se os gramscianos latino-americanos encontraram a resposta à crise teórica no vínculo entre teoria e política, isso foi possível - como pretendo mostrar - não porque lhes faltasse a teoria, mas porque a tradição de 
recepção do pensamento de Gramsci na América Latina foi sempre caracterizada por uma leitura em chave política, e assim foi desenvolvida.

Dito isso, gostaria de sublinhar aquela que considero ser a primeira característica fundamental dessa escola: o vínculo com a política; com isso me refıro, todavia, não tanto à ligação com a "ciência política" ou a "sociologia política", mas, antes, ao envolvimento íntimo com a "política” tout court, com a ação, com a práxis política. E não é por acaso que a figura de Aricó ${ }^{6}$ possa ser pensada como um elemento central na elaboração dessa nova perspectiva teórico-política, sendo ele representante e mediador de uma linha que, partindo de Héctor Agosti, encontra inspiração e fundamento na práxis do ativismo político revolucionário, mais do que na universidade e nas discussões acadêmicas?

Com base no dito acima, no meu entender, a segunda característica mais importante pode ser encontrada na pluralidade das linhas teóricas interpretativas, na interrelação entre as diversas abordagens da herança gramsciana; para dizê-lo ao modo latino-americano, na “mestiçagem teórica". Por diversas vias, foi (e ainda é) invocada a produção de um "marxismo latino-americano", um marxismo "indo-americano", etc., e - esse é o ponto central - o marxismo de Gramsci, pela sua natureza, permitia a realização dessa operação.

Como terceira característica fundamental, em termos metodológicos, gostaria de assinalar um uso específico da teoria gramsciana da "tradutibilidade", que se entrelaça com outras perspectivas para constituir o que poderíamos denominar como "tradutibilidade antropofágica", característica que discutiremos mais adiante.

Nesse sentido, nesta tentativa de interpretação procurarei delinear alguns "afluentes" que contribuíram para a formação da escola latino-americana da hegemonia, distinguindo entre "afluentes nacionais" e "afluentes temáticos" que, se minha interpretação é relativamente válida, se intercruzaram ao longo de seu percurso para constituí-la. No volume Gramsci in America Latina, organizado por Dora Kanoussi, Giancarlo Schirru e Giuseppe Vacca (2011), pode- 
mos encontrar uma primeira fonte desses afluentes nacionais, aos quais tentarei acrescentar outros.

Para esse objetivo, tentarei realizar aqui uma exposição esquemática, sem qualquer pretensão de exaustividade (impossível no espaço deste artigo, dada a dimensão do fenômeno), mas suficientemente ampla para não deixar de mencionar correntes e autores que marcaram a história da recepção do pensamento gramsciano na América Latina. Essa descrição será "esquemática”, descritiva, porque tem somente o objetivo de fornecer uma breve ideia "impressionista" do denso patrimônio acumulado, dando conta da variedade e da localização geográfıca, da produção teórica. Nesse sentido, limitar-me-ei a citar alguns autores a partir de suas obras mais importantes, sem entrar em qualquer valorização crítica - salvo algumas breves menções -, desculpando-me, desde já, por eventuais omissões. De fato, penso que a própria descrição dos "afluentes" por meio dessas menções a autores e obras, ainda que sem discussão crítica, possa ser, mesmo assim, útil para conferir um primeiro significado coletivo a esta vasta, e necessariamente dispersa, produção intelectual.

Nesse sentido, não pretendo apresentar neste trabalho um exercício de "história das ideias", mas, antes, utilizar a ideia de "mapa bibliográfico" - realizado pelo grupo dirigido por Giovanni Semeraro na Universidade Federal Fluminense, para expor o corpus da bibliografia gramsciana no Brasil (ver nota 10) -, com o intuito de traçar os contornos do fenômeno que me interessa delimitar. No seminário de Urbino, procurei implementar "fisicamente" esta ideia, apresentando um mapa dos principais autores e temas enfrentados, intentando aproximar os participantes do seminário ao tema por meio de uma "espacialização" da produção teórica citada. Considero que, na América Latina, onde estão em curso processos de organização, institucionalização e intensas trocas entre pesquisadores gramscianos de diversos países ${ }^{8}$, esta ideia de espacialização da produção intelectual, de um “mapa”, poderia dar lugar a iniciativas colaborativas análogas à Wikipedia, fornecendo 
um instrumento interativo eficaz para o conhecimento dos autores e da sua bibliografia, permitindo o acesso direto via web. No curso do seminário de Urbino se falou da possibilidade de elaboração de um instrumento técnico desse tipo, para favorecer o acesso à bibliografia mundial gramsciana inicialmente sistematizada por John Cammet, hoje atualizada sob responsabilidade da Fondazione Gramsci. Em todo caso, a exposição estruturada em torno da ideia de "afluentes nacionais" foi pensada também com esse objetivo técnico.

\section{Afluentes nacionais}

\section{Argentina}

Um primeiro afluente nacional a mencionar é o argentino. Com Martín Cortés, na ocasião da conferência Egemonia e modernità, ocorrida em Roma, em maio de 2017, tentamos descrever as diversas "heranças" dessa variante nacional, que almejo aqui apenas mencionar, sem me deter nos detalhes ${ }^{9}$.

a) A corrente agostiana, originada nos trabalhos de Héctor Agosti, à qual se relacionam numerosos autores (por exemplo, Néstor Kohan, 2004; Mabel Thwaites Rey, 1994; Daniel Campione, 2007; Gastón Varesi, 2015, etc.); b) A corrente pasadopresentista (pautada nos trabalhos de José Aricó, Juan Carlos Portantiero e o grupo de "Pasado y Presente"), na qual podemos incluir autores como Horacio Crespo, 2001; Martín Cortés; Javier Rovelli, 2018; Juan Jorge Barbero, 2016; Sebastián Gómez, 2015, e muito outros; nessa vertente incluo minha própria intervenção, apesar de reconhecer a influência de outras correntes; c) o gramscismo peronista (John William Cooke, 1973; Horacio Conzález, 1971, 2015), na qual podemos inserir autores como María Pía López, 2015; Mario Della Rocca, 2014, etc.); d) aquela que indicamos como via laclausiana do gramcismo argentino (obviamente, nos referimos ao trabalho de Ernesto Laclau e dos seus discípulos), na qual destacamos o trabalho de Javier Balsa (2006, 2019a), que tem realizado contribuições teóricas e metodológicas à teoria da hegemonia a partir dessa perspectiva; e) al- 
gumas correntes recentes do gramscismo argentino, entre as quais: i. aquelas ligadas à movimentos e espaços políticos que reivindicam uma prática territorial vinculada à auto-organização e à autonomia (o trabaIho de Miguel Mazzeo, 2014 e Hernán Ouviña, 2017, etc.); ii. aquela que vê uma ligação entre Gramsci e Trotsky, por meio do prisma de leitura da relação entre hegemonia e revolução permanente (fundamentalmente, os livros de Juan dal Maso, 2016, 2018). Certamente, podemos mencionar contribuições teóricas que dialogam com mais de uma dessas correntes, como o trabalho de Waldo Ansaldi, Néstor García Canclini, José Nun e outros. Nos últimos anos, surgiu uma nova geração de gramscianos bem representada na atual composição da refundada Asociación Gramsci Argentina. Parece-me importante, por fım, citar alguns autores que se ocuparam da experiência argentina na Itália, como Fabio Frosini (2017), Pasquale Serra (2019) e o jovem pesquisador Alessandro Volpi (2019). Entre as principais temáticas elaboradas em nível nacional na Argentina, podemos citar: a independência nacional e a "revolução ausente"; o nacional-popular e o "nacionalismo revolucionário"; o populismo; a discussão acerca do "subalterno", a subalternidade e as massas marginais; a autonomia e a autodeterminação; a relação entre democracia e socialismo; a questão da tradutibilidade; a teoria da hegemonia; a relação Gramsci-Mariátegui, etc.

\section{Brasil}

O Brasil se distingue pela peculiar multiplicidade de leituras de Gramsci, razão pela qual é difícil e arriscado tentar enunciá-las e classificá-las, ainda que existam alguns trabalhos sobre a recepção de Gramsci no Brasil (Carlos Nelson Coutinho, 1986; Ivete Simionatto, 1995, 2019; Lincoln Secco, 2002; Alvaro Bianchi, 2011), que constituem referências fundamentais. Do ponto de vista historiográfico, a recepção de Gramsci no Brasil foi marcada, em um primeiro momento, pela disputa entre gramscianos provenientes da experiência do Partido Comunista Brasileiro e as outras correntes interpretativas. Nos 
últimos anos, penso, essa distinção perdeu sua força e, na variedade das interpretações que encontramos hoje, a dimensão teórica do debate parece ter adquirido uma maior centralidade, em detrimento do pertencimento partidário. Nesse sentido, considero que uma análise exaustiva das diversas correntes teóricas está ainda por ser realizada, o que, obviamente, não constitui o objetivo deste trabalho.

$\mathrm{Na}$ tentativa de delinear a especificidade do afluente nacional brasileiro, gostaria de partir de Carlos Nelson Coutinho, cuja obra - que tratou de uma ampla variedade temática - tem a peculiaridade de relacionar o pensamento de Gramsci com o de Lukács. No meu entendimento, do ponto de vista da teoria da hegemonia, uma das contribuições mais importantes de Carlos Nelson Coutinho à recepção de Gramsci na América Latina é dada pelo conceito de "reformismo revolucionário" (que Coutinho toma de André Corz), mediante o qual atualiza a temática da teoria da revolução como hegemonia, abordada também pelo grupo argentino de "Pasado y Presente" naqueles mesmos anos. Outras contribuições fundamentais de intelectuais também provenientes do Partido Comunista Brasileiro (PCB), são as de Marco Aurélio Nogueira (1988; 2004), concentrado no estudo da política e das instituições políticas; Marco Del Roio $(2005,2018)$, que trata de temas como socialismo e comunismo, as classes subalternas e a superação da subalternidade; Luiz Werneck Vianna (1997) e Alberto Aggio (1998), com trabaIhos marcados pela temática da revolução passiva; Milton Lahuerta (1998), que analisa a questão dos intelectuais; e outros.

Entre os expoentes das várias correntes de recepção da obra gramsciana fora do PCB, encontramos o trabalho de Edmundo Fernandes Dias (1996, 2000, 2012), com um legado caracterizado pelo estudo do jovem Gramsci e a questão dos conselhos de fábrica e da autonomia, posteriormente reivindicado por pensadores gramscianos de matriz trotskista como Alvaro Bianchi (2008, 2011) e Ruy Braga (2010). No âmbito do estudo dos movimentos sociais, da sociedade civil e das 
questões da cidadania, é fundamental assinalar o trabalho de Evelina Dagnino (2002), atentíssima leitora de Gramsci.

No interior do Partido dos Trabalhadores, desenvolveu-se uma importante discussão sobre Gramsci, amplamente descrita por Eric Coimbra (2017); na esfera desta vasta experiência, teórica e política, é imperativo mencionar os trabalhos de Tarso Genro (1990) e de Emir Sader (2005).

Outro fundamental ponto de referência é aquele representado pelo trabalho de Giovanni Semeraro $(2006,2009)$ que, a partir da filosofia, desenvolveu um diálogo intercruzado entre a teologia da libertação, o pensamento de Paulo Freire e outros temas, entre os quais o tema das classes subalternas no Brasil e a questão do nacional-popular.

O desenvolvimento de um intenso uso "disciplinar" do pensamento de Gramsci, que temos assistido nos últimos trinta anos no Brasil, constitui uma característica, a meu ver, muito peculiar. Entre as disciplinas interpeladas pelo debate gramsciano podemos mencionar: a ciência política (Daniela Mussi, 2014; André Kaysel, 2019; Leandro Galastri, 2019; Camila Góes, 2016; Luciana Aliaga, 2017; Sabrina Areco, 2019; Victor Gomes, 2015; Jefferson R. Barbosa, 2015; Geraldo Magella Neres, 2012; etc.); a sociologia (Edmundo Fernandes Dias, 2000; Francisco de Oliveira, 2010; Claudio Reis, 2020); a filosofia (Giovanni Semeraro, 2006, 2009; Maria S. Militão, 2019, Gianni Fresu, 2017); a pedagogia (Demerval Saviani, 2009; Paolo Nosella, 2004; Anita Helena Schlesener, 2001, 2009, 2016; Rosemary Dore Soares, 2000; Cézar de Mari, René Trentin, 2018; Marcos Francisco Martins, 2008; Joeline Rodrigues, Deise Rosálio, 2018, e diversos outros autores); o serviço social (Alba Maria de Carvalho, 1982; Ivete Simionatto, 1995; Maria Lúcia Duriguetto, 2007; Marina Maciel Abreu, 2002; Ana Lole, 2018, Josimeire Leite, 2017 etc.); os estudos sobre relações internacionais (Leonardo Ramos, 2013; Rodrigo Passos, 2013); a historiografia (Lincoln Secco, 2002; Riccardo Salles, 2012; Virginia Fontes, 2018); o direito (Edmundo Arruda Júnior, 1995; María del Carmen Cortizo, 2006; Adriano Nascimento, 
2017); a psicologia (Erasmo Miessa Ruiz, 1998); a geografia (Marcos Aurelio Silva, 2013) e, seguramente, outros campos de estudos e intervenções individuais que escapam de minha tentativa descritiva. Essa variedade de corrente e interpretações contribuiu para a peculiar multiplicidade de leituras gramscianas no Brasil, expressa por uma plêiade de novos autores que se referem ao pensamento de Gramsci, conforme evidenciado no referido mapa bibliográfico elaborado pela Internacional Cramsci Society - Brasil ${ }^{10}$.

\section{México}

Em terceiro lugar, gostaria de mencionar o afluente nacional mexicano, já objeto de algumas tentativas de descrição, como aquelas de Arnaldo Córdova (1988), de Dora Kanoussi (2011a), de Jaime Ortega Reyna (2015) e, mais recentemente, de Diana Fuentes y Massimo Modonesi (2020). Este afluente é caracterizado, penso, por um elemento temático estabelecido no início dos anos 1980, com a obra de Javier Mena e Dora Kanoussi (1985) sobre o conceito de Revolução Passiva, que marcou de maneira significativa o gramscismo latino-americano. A reflexão sobre esse conceito não era nova - penso, por exemplo, nos trabalhos de Agosti e Portantiero, na Argentina, e de Werneck Vianna e Carlos Nelson Coutinho, no Brasil - se bem que a análise de Kanoussi e Mena, talvez em virtude particular experiência mexicana, atingiu um ponto de altíssima qualidade; provavelmente não seja por acaso que Massimo Modonesi (2017) continua a desenvolver a temática de modo singular, debruçando-se particularmente sobre os temas da subalternidade e da autonomia. A questão da revolução passiva se tornará fundamental para a escola latino-americana da teoria da hegemonia, assim como a temática do Estado integral discutida por Lucio Oliver (2009). Em 2018, foi fundada a Asociación Gramsci México, que reúne diversos pesquisadores, entre os quais Diana Fuentes (2018), Elvira Concheiro (2013) e outros, que continuam a desenvolver esta escola de pensamento nesse país. 


\section{Região andina: Peru, Bolívia, Equador}

Em quarto lugar, considero importante mencionar (e valorizar corretamente) a contribuição à formação da escola latino-americana da hegemonia realizada desde a região andina, marcada pela influência da tradição mariateguiana (aquela legada pelo pensador marxista peruano José Carlos Mariátegui). E não apenas pelas relações entre Mariátegui e Gramsci, que têm origem na sua "difusão conectada" - ou seja, o impulso recíproco da circulação de suas ideias, como mostrado por Aricó (1980) e Robert Paris (1983): de Mariátegui herdamos um modo radicalmente heterodoxo de pensar as classes subalternas e o sujeito da transformação socialista, que no Amauta se torna socialismo indo-americano. Vários autores trabalharam, posteriormente, com a interseção teórica entre Gramsci e Mariátegui, entre os quais Francis Guibal (1981), César Lévano (1979) e Alfonso Ibañez (1979). E é um fato curioso neste sentido que o primeiro a definir Mariátegui como o "primeiro marxista da América" tenha sido um italiano, o crítico literário Antonio Melis (1978 [1969]).

Em relação a esse afluente, é imprescindivel mencionar a particular intervenção de matriz gramsciana do pensador boliviano René Zavaleta Mercado (1988, 1990), sobretudo sua teorização sobre a questão do "Estado" na América Latina e suas conclusões sintetizadas nos conceitos de formação social "abigarrada" e de "Estado aparente"11, que dialogam com os conceitos de "Estado integral" e de "bloco histórico", elaborados por Gramsci. É mister, ainda, realizar uma valorização plena da influência das ideias de Zavaleta Mercado na América Latina dos anos 80 (a influência registrada na Bolívia é indubitável) e na formação da escola latino-americana de hegemonia, embora já contemos com um importante movimento intelectual nessa direção (por exemplo: Giller, 2016; Guiller e Ouviña, 2016). Na linha do desenvolvimento dessa tradição encontramos os trabalhos de Álvaro García Linera (2010, 2015) e Luis Tapia (2002), de particular importância no interior desse "afluente". 
Sobre a recepção e difusão do pensamento de Gramsci no Equador, devo mencionar, fundamentalmente, os trabalhos de Francisco Hidalgo Flor (2005), marcado pela discussão em torno da subjetividade indígena no processo de transformação social; e de Santiago Ortiz (2018), orientado ao estudo dos movimentos populares.

Este afluente aborda várias temáticas de altíssimo interesse e atualidade, entre as quais: uma visão original das classes subalternas; o Socialismo Indo-americano; a interrelação entre nacional-popular e nacionalismo revolucionário; as formações sociais "abigarradas", o Estado aparente; o neoconstitucionalismo, o “bem viver”, etc.

Penso que esses sejam os quatro afluentes fundamentais; não obstante, outras correntes importantes devem ser abordadas suscintamente.

\section{Chile}

Em torno do afluente chileno, devem ser mencionados autores como Osvaldo Fernández Díaz, Juan Eduardo García-Huidobro, Carlos Ossandón, Enzo Faletto, Antonio Cortés Terzi, Jaime Massardo e outros, que representam uma história específica da recepção. Massardo (2011) realizou uma primeira sistematização de autores e temáticas em que se evidencia o nexo fundamental com a política. Como o próprio Massardo indica, depois de uma intensa difusão e discussão do pensamento gramsciano na longa transição dos anos 80 , os anos 90 são caracterizados por um verdadeiro silêncio, enquanto no novo século se assiste a um novo início. Osvaldo Fernández Díaz (1971) e Gonzalo Ossandón Véliz (2020) junto com a Editorial Popular La Pajarilla (2020), realizam nos tempos atuais um relevante trabalho de reflexão teórica, difusão e organização dos estudos gramscianos nesse país andino. Autores como Oscar Ariel Cabezas (2015), sublinham a emergência de uma nova geração de estudiosos gramscianos interessados em valorizar o vínculo profundo com a política; "o pensamento entrelaçado com a política”, como sublinha Cabezas (2015, p. 11). 


\section{Cuba, Caribe e outros países centro-americanos}

Encontramos outro afluente, no interior da revolução cubana, nas leituras gramscianas de Martínez-Heredia, Jorge Luis Acanda e outros. No artigo Gramsci en la Cuba de los años Sesenta, publicado pela primeira vez em 2003, Martínez-Heredia faz um breve relato daquilo que considera um emprego precoce dos instrumentos teóricos gramscianos no interior do jovem processo revolucionário cubano, na segunda metade dos anos 1960. "A heresia cubana" - afirma Martínez-Heredia (2018, p. 182) - “absorveu Cramsci com naturalidade” naquela fase da revolução. "Gramsci foi uma das armas intelectuais da primeira fase da revolução no poder" (2018, p. 188); infelizmente, aquela etapa chegou ao fim "quando teve início a segunda fase [...], funesta para o pensamento social [...], Gramsci tornou-se um estrangeiro em Cuba" (2018, p. 188). Jorge Luis Acanda (2006) desenvolve, ulteriormente, essas conclusões de Martínez-Heredia. "O início da segunda fase da revolução [...] em 1971, com o fechamento da revista 'Pensamiento Crítico'”, levou a uma situação na qual "o marxismo dogmático se apoderou de todas as esferas [...]. Todo uso de - ou mesmo referências a - autores do marxismo crítico, incluído Gramsci, foi banido" (ACANDA, 2006, p. 217). Posteriormente, a partir dos anos de 1985-1986, teria início a «terceira fase da revolução e, durante essa, nos anos 1990, em Cuba se voltou a falar de Gramsci, fundamentalmente por meio da discussão sobre o conceito de sociedade civil (ACANDA, 2006, p. 219).

A fundação da Cátedra de Estudios Antonio Gramsci, no Centro de desarrollo e investigación de la Cultura Cubana Juan Marinello, foi um ponto alto desse novo momento. Desde seu início, o Centro Marinello promoveu a discussão e a difusão do pensamento gramsciano, o que levou à publicação dos volumes Hablar de Gramsci (ESTEVA-PARODI, 2003), Gramsci: los intelectuales y la sociedad actual (ESTEVA-PARODI, 2006) e outros.

No que se refere à Jamaica, é indispensável mencionar o trabalho de Stuart Hall no âmbito dos Estudos Culturais ingleses. Não é o caso 
de retomar aqui o pensamento de Hall acerca de Gramsci - expresso no conjunto da sua obra, e, mais especificamente, em textos como Cramsci and us ou Gramsci's Relevance for the Study of Race and Ethnicity -, mas, antes, de afırmar o pertencimento deste autor à discussão que aborda as grandes questões do movimento histórico na América Latina e o Caribe. O pensamento de Hall (assim como o de Laclau, Michael Löwy, Fanon e outros) levam a marca de sua origem latino-americana. Na última seção retornarei a esse ponto na discussão de algumas teses de Walter Mignolo sobre a recepção do pensamento de Gramsci na América Latina.

Sobre a recepção do pensamento de Gramsci em El Salvador já escrevi algumas notas, particularmente em As peripécias de Gramsci entre Gulliver e o Pequeno Polegar (1994), onde pretendi mostrar como, uma vez terminada a guerra civil, foi tentada por alguns autores a utilização de novas categorias teóricas - entre as quais aquelas gramscianas -, no desenvolvimento de uma estratégia adequada à continuação do processo revolucionário depois dos acordos de paz. Alguns desses autores (CIENFUEGOS, 1986; MEDRANO, 1992) utilizaram os conceitos elaborados por Gramsci, com êxitos diversos. Em particular, gostaria de mencionar aqui o trabalho de Borki Ulianov Tacatic Cáceres, Aplicaciones del concepto de revolución de Antonio Gramsci a El Salvador, tese de graduação defendida em março de 1993; um ano depois, em maio de 1994, o autor, militante pelos direitos humanos e coordenador da União Nacional dos Refugiados, Repatriados e Deslocados de El Salvador, foi assassinado pelos paramilitares ${ }^{12}$.

Não obstante esses esforços, todavia, a experiência mostra que a transição de uma modalidade de pensamento estratégico marcado pela luta armada para um pensamento estratégico caracterizado pela luta pela hegemonia não foi completada, mantendo-se, penso, como uma necessidade do processo. Entre as temáticas discutidas na experiência salvadorenha, podemos mencionar: a relação revolução-hegemonia e sociedade civil-Estado ampliado; a teoria do partido político; 
a crise orgânica; a relação do pensamento de Gramsci com a teologia da libertação e o uso do pensamento de Gramsci por parte dos jesuítas centro-americanos, etc.

\section{Colômbia e Venezuela}

Nos últimos anos, se desenvolveu um importante trabalho de discussão e difusão do pensamento de Gramsci na Colômbia, a partir da experiência do "Seminário Internacional Gramsci", que tem ocorrido desde 2008 (chegando, hoje, à sua XVI edição), coordenado por Miguel Angel Herrera Zgaib, que trabalha com as temáticas das classes subalternas, da autonomia, da hegemonia, do intelectual orgânico e sobre aquilo que Herrera Zgaib (2015) define como "pensamento de ruptura”. Na Colômbia se constituiu, de fato, uma tradição gramsciana, que, a partir de 1991, com as primeiras tentativas de organização de uma Sociedad Colombiana Antonio Gramsci, coordenada por Jorge Gantiva Silva, chegou, em 2016, à fundação da Sociedad global Gramsci. O livro Antonio Gramsci. Subjetividades e saberes sociales (2016), organizado por Yolanda Rodríguez-Rincón e Giovanni Mora Lemus, reúne textos de vários intelectuais dessa nova geração de gramscianos colombianos.

No caso da Venezuela, se desenvolveu um uso de Gramsci no interior das reflexões sobre as particularidades da dita revolução bolivariana; o próprio presidente Hugo Chávez o utilizou como chave explicativa em diversas ocasiões, em particular nas grandes manifestações populares ocorridas em Caracas em 2 de junho de 2007, em apoio à decisão do governo de não renovar a concessão à rede televisiva Radio Caracas Televisión (RCTV), fechada em 27 de maio daquele ano. As manifestações, das quais participaram centenas de milhares de pessoas - mais de um milhão, estimaram algumas fontes (MAIRA, 2007) - se conclui com um longo discurso de Hugo Chávez, no centro de Caracas: uma verdadeira aula de massas sobre o pensamento de Gramsci, em que o revolucionário bolivariano explica conceitos como estrutura e superestrutura, vontade coletiva, crise, bloco 
histórico, hegemonia, sociedade política e sociedade civil, ideologia, etc. Chávez conclui o comício também citando Gramsci: "construindo a pátria, construindo a nova Venezuela, continuamos, portanto, segundo o ponto de vista gramsciano, a enterrar o velho bloco histórico, e a construir um novo" (FOLLIE, 2007)13. Num breve, mas contundente, artigo intitulado A Venezuela e Gramsci, o jornalista brasileiro Breno Altman (2017) se refere à Venezuela como "o maior laboratório para o pensamento de Gramsci da história" e, de frente aos desafios atuais do processo venezuelano, sustenta que a Venezuela "tem uma possibilidade real de triunfo, se seguir rigorosamente as recomendações de Cramsci". Nesse sentido, além dos temas mencionados, na Venezuela foi crucial a discussão sobre as relações entre socialismo e democracia. Intelectuais como os ítalo-venezuelanos Jorge Giordani (2009) e Alberto Filippi (2017), e os argentino-venezuelanos Hugo Calello e Susana Neuhaus (2010) contribuíram para a difusão e o debate sobre o pensamento gramsciano na Venezuela.

\section{Afluentes temáticos}

O conjunto (obviamente incompleto) de afluentes nacionais e autores que citei até aqui contribuíram para configurar a experiência que é objeto deste artigo. Costaria, agora, de passar a sublinhar alguns afluentes temáticos que considero igualmente fundamentais.

Em primeiro lugar, deve ser considerada a questão das subjetividades coletivas envolvidas no processo de transformação social. A respeito daquilo que, no âmbito gramsciano, é debatido geralmente como "classes e grupos subalternos", a América Latina deve enfrentar, de um lado, uma série de problemas que podem ser considerados apenas parcialmente "nossos", sendo partilhados também com outros países do capitalismo "periférico", incluindo a Itália da época de Gramsci. De outra parte, porém, há outras que portam inequivocamente a marca da nossa especificidade; por exemplo, a questão dos "povo originais" ou, em outras palavras, as consequências do verda- 
deiro genocídio produzido pela invasão europeia sobre a população e sobre os sistemas políticos e sociais no interior do território conhecido como "América" - um nome dado por engano, como é sabido - e que seria preferível chamar de Abya Yala ${ }^{14}$; ou aquelas questões relativas à longa história de escravidão que remonta à invasão europeia da África e ao sequestro e comércio de milhões de homens, mulheres e crianças negras ${ }^{15}$; o desenvolvimento desigual e "descombinado" (Pomar, 2019) do capitalismo. Se trata de problemas que a Europa experimentou de modo distinto, ou que não experimentou absolutamente, como aqueles da escravidão moderna e das populações indígenas.

Isso nos remete ao tema das massas marginais, segundo o conceito do sociólogo gramsciano argentino José Nun (1969). Essas massas marginais, resultado do processo descrito acima nunca existiram, de fato, na Europa, uma vez que o capitalismo central foi capaz de absorver, em tempos de crescimento e de modo relativamente pleno, a força de trabalho livre, mantendo um sólido exército de reserva. É a discussão tratada por Marx no capítulo 23 de O capital, a respeito da superpopulação relativa. Na América Latina (e em outras regiões do mundo, obviamente), aquela massa é "marginal”; são milhões, enormes massas populacionais em excesso absoluto, como foi dito: do ponto de vista da elite racista latino-americana, são gente demais, e, portanto, devem ser excluídos. E o trabalho de pensar a respeito dessas massas não foi bem desenvolvido no interior do marxismo latino-americano, com a exceção do marxismo "herético" de Mariátegui. O aparato teórico para se pensar a origem e o papel dessas massas veio in primis de outras fontes: de uma parte, do anarquismo, do nacionalismo revolucionário, da teologia da libertação, da corrente pedagógica que se inspira em Paulo Freire, daqueles que pensavam em chave "populista". Mais tarde, o marxismo latino-americano assumiu a tarefa de pensar de um modo distinto a respeito desses complexos contingentes sociais.

Em relação a este ponto, a categoria gramsciana de classes subalternas $^{16}$ se entrelaça (ao mesmo tempo constituindo sua base) com a 
intervenção fundamental de Mariátegui, Zavaleta Mercado, Aricó etc., quando refletem sobre o papel desses grupos sociais no processo de formulação do projeto socialista. E aqui, precisamente, encontramos a intervenção fundamental de Mariátegui (1987 [1928]), que localiza o sujeito do socialismo peruano na própria comunidade dos povos originais. A questão da história e papel desses povos é um problema extremamente relevante para o tema que tratamos; não apenas enquanto componentes das massas marginais, mas, fundamentalmente, creio, em termos estratégicos; por exemplo, do ponto de vista ecossocialista, quando se pensa os sistemas indígenas de produção como modalidade específica de relação entre homem e natureza, por meio da temática discutida como "o bem viver", ou, para pensar a questão democrática para além da limitada matriz liberal que formatou os sistemas políticos latino-americanos desde sua fundação. Nesse sentido, as experiências boliviana e equatoriana são fundamentais.

Devo mencionar também outros afluentes temáticos específicos, como a particular questão do Estado e dos processos de modernização na América Latina do século XX, ligada a problemas discutidos por Gramsci por meio do conceito de "revolução passiva"; a discussão sobre a forma de relação política, geralmente definida, de modo pejorativo, como "populismo", analisada recorrendo a conceitos como "cesarismo", "bonapartismo" etc., mas que se refere essencialmente à questão da representação daquele povo difuso e desagregado, a qual, a meu ver, Ernesto Laclau enfrentou melhor do que qualquer outro, com uma teoria de indubitável profundidade; por fim, outros problemas específicos, como:

i) o tema da religião - ou seja, a nossa "questão vaticana" específica -, que se tornou extremamente complexa na América Latina por causa do sincretismo religioso (da "mistura" toda nossa), da influência evangelista norte-americana, sobretudo do neopentecostalismo - a dita "religião da prosperidade" -, de fortíssimo caráter conservador; ii) a questão do partido com suas diversas variantes, entre as quais o 
partido moderno clássico, o novo partido-frente e/ou partido-movimento, de importância fundamental na experiência latino-americana; iii) a particularidade da questão feminina e a intersecção do feminismo com as temáticas precedentemente mencionadas, que produziu resultados particularmente importantes do ponto de vista da transformação social radical-democrática.

Penso que as abordagens teóricas específicas descritas, surgidas a partir do uso diversificado do arcabouço teórico gramsciano no interior do marxismo, para afrontar esse conjunto de problemas constituem uma série de ideias que nos permitem definir os contornos da escola latino-americana de hegemonia.

\section{A tradutibilidade, a antropofagia e a mestiçagem como características da recepção de Gramsci: dois manifestos}

$\mathrm{Na}$ tentativa de expor e articular esta série diversificada de afluentes nacionais e temáticos entrecruzados, procurei também recuperar autores nascidos e crescidos nesta terra, e que produziram, fora da América Latina, teorias originais marcadas pelo contexto geográfico e pelas problemáticas comuns da América Latina. Com Martin Cortés, no artigo já mencionado, discutimos criticamente a ambição, a voracidade, com que Perry Anderson, no texto The Heirs of Cramsci (2016), procura apropriar-se das teorias de Arrighi, Guha, Laclau, Stuart Hall, cuja obra ele vê "aflorar" no campo "anglófono", principalmente britânico. Anderson, com evidente eurocentrismo, gostaria de assimilar tais heranças em chave anglófona. Penso, então, que podemos caminhar no sentido contrário ao de Anderson, e, legitimamente, reabsorver os nossos teóricos no campo do gramscismo latino-americano: Stuart Hall, Ernesto Laclau, Michael Löwy; mas, também - numa outra chave imanente ao processo de elaboração de uma teoria da emancipação - Franz Fanon e outros.

Durante o Coloquio Internacional Antonio Gramsci, ocorrido em Campinas, Brasil, em agosto de 2017, a intervenção de Bernardo Ri- 
cupero, Antonio Gramsci e Oswald de Andrade: ou tradução e antropofagia, propôs um vínculo entre a teoria da tradutibilidade ${ }^{17}$, elaborada por Gramsci nos Quaderni, e o procedimento “antropofágico" enunciado no Manifesto de Oswald de Andrade, para pensar a difusão do pensamento de Gramsci no Brasil. Essa intuição sagaz de Ricupero abre uma via utilíssima para analisar a recepção do pensador sardo na América Latina, e, nesse sentido, podemos recorrer à relação tradutibilidade/antropofagia, entendida como método adotado pelos latino-americanos para poder se relacionar autonomamente com a cultura europeia: “a antropofagia nos une”, sustenta Andrade (1978, p. 13).

Uma contribuição posterior de Ricupero, atento leitor de Gramsci, foi de grande ajuda para avançar nesta linha interpretativa. O autor sublinha que "Oswald de Andrade imagina a inversão da forma como a sua nação e, num sentido mais amplo, o que chama de América se relaciona com a Europa” (RICUPERO, 2018, p. 892). “O Manifesto Antropofágico, em particular, defende una inversão da subordinação entre Europa e América" (RICUPERO, 2018, p. 879) e, nesse sentido, não é difícil "encontrar afınidades com o que hoje é chamado de pós-colonialismo, especialmente no sub-ramo dos estudos subalternos" (RICUPERO, 2018, p. 876), ou, mais explicitamente, “como crítica pós-colonial avant la lettre" (RICUPERO, 2018, p. 879).

Em termos metodológicos, já que, para Andrade (1929, p. 3), “todo progresso real humano propriedade do homem antropofágico (Galileu, Fulton etc." (apud RICUPERO, 2018, p. 882), Ricupero assinala que a "antropofagia estaria especialmente aberta a diferentes influências e à inovação" e, quando Andrade discute o significado de "antropofagia" na Revista Antropofágica Sucursal do Rio, recorda que a visão própria da revista "é basicamente como síntese, num sentido próximo à mestiçagem" (RICUPERO, 2018, p. 890, grifos nosso).

De fato, isso nos aproxima de uma questão metodológica central para a escola latino-americana: o conceito e o projeto gramsciano da tradutibilidade. Nesse sentido, em relação à antropofagia como 
síntese e/ou mestiçagem, Ricupero indica que o procedimento antropofágico "a Antropofagia modifıca a questão do 'original' e da 'cópia', ao indicar metaforicamente que o próprio ato de devorar algo transforma aquilo que se come [...] a deglutição conduz a uma certa síntese como indica, por exemplo, a ideia de mestiçagem"; ou, ainda: "Radicalizando tal perspectiva, se pode argumentar que a Antropofagia, em sua ânsia de 'descentramento', transcende o ambiente brasileiro e periférico, convertendo-se, como quer João Cezar de Castro Rocha (2011: 648), em 'promessa de uma imaginação teórica da alteridade, mediante a apropriação criativa da contribuição do outro'" (RICUPERO, 2018, p. 892). Parece-me que a relação entre projeto antropofágico e projeto gramsciano de tradutibilidade seja evidente, ao menos para os latino-americanos ${ }^{18}$.

Consciente do fato de que propor essas grandes articulações e um programa de pesquisa de uma pluralidade assim tão grande requer não apenas uma soma algébrica de questões e problemas, mas uma nova síntese - que deverá ter procedimentos, de algum modo, "antropofágicos" -, gostaria de sublinhar que o marxismo de Gramsci procede, podemos dizer, desta maneira: se apropria e reelabora, a seu modo, categorias que são dos outros, inclusive dos adversários teóricos; e é por isso que se demonstrou útil para pensar a sociedade latino-americana e suas transformações. A esse respeito, se pode citar alguns exemplos fundamentais: Gramsci toma a ideia de revolução passiva de Vicenzo Cuoco, e de revolução-restauração de Edgar Quinet, reelaborando-as como componentes da teoria da hegemonia; partindo da noção de "bloco", de Georges Sorel, a reabsorve no conceito de bloco histórico; elaborando a ideia de reforma intelectual e moral de Ernest Renan, a transforma no conceito central para designar a elevação intelectual e moral das massas, essenciais para o processo de construção hegemônica; apropriando-se da concepção de sociedade civil de Hegel, a converte em um ponto crucial da sua teoria do Estado integral etc; toma a noção parcial e restrita de hegemonia da 
socialdemocracia russa e a transforma, laboriosamente, em um ponto central das próprias reflexões no cárcere. O próprio Ricupero (2018, p. 895), citando um diálogo de Margaret Leslie com Quentin Skinner sobre o fato de que "a história pode servir como uma espécie de reserva de material quase inigualável para formulações teóricas", sugere que um «exemplo de tal procedimento, que fornece argumentos em favor de um certo anacronismo, é a maneira de Antonio Gramsci se servir das reflexões de Nicolau Maquiavel para elaborar, de maneira extremamente original, sua própria teoria». São muitos os exemplos possíveis, mas creio que aqueles acima citados são os fundamentais. No Dizionario gramsciano (LICUORI; VOZA, 2009), podemos observar uma série de transformações conceituais que nos mostra como o processo de absorção e reelaboração seja vital para a construção do pensamento gramsciano; um verdadeiro procedimento “antropofágico", para dizê-lo em chave latino-americana.

Entretanto, no momento da elaboração deste esquema de pesquisa em curso, me deparei com um trabalho que, de modo diverso, se move em uma direção similar: refiro-me ao texto de Hernán Ouviña, Indigenizar el marxismo. Apuntes para descolonizar los proyectos emancipatórios, que, desde o início, li em chave de "manifesto". Ainda que não possa aprofundar o ponto, gostaria de citar algumas das proposições de Ouviña (2017, s. p.):

Um dos maiores erros do socialismo como projeto de civilização alternativa foi ter privilegiado a endogamia teórica e prática na tentativa de promover horizontes de emancipação; nesse sentido, consideramos que ele deveria se nutrir de outras experiências e conhecimentos, entre os quais se encontram aquelas elaboradas e defendidas pelos vários povos indígenas que habitaram por séculos, e que estão ainda presentes, em toda a Nossa América. Em suma, se trata de ser voluntariamente adúlteros e mestiços, abrindo-nos para indigenizar o marxismo [...] reivindicar uma leitura simbiótica com as tradições afrodescendentes, 
camponesas e indígenas no interior do marxismo [...]. Portanto, devemos descolonizar o marxismo [...] indigenizá-lo, obviamente, mas também enegrecê-lo e despatriarcalizá-lo.

Notamos, portanto, como, numa outra forma literária e com objetivos estratégicos diferentes, assim como o "manifesto antropofágico" de Oswald de Andrade, o texto de Ouviña também pode ser lido, de fato, como manifesto "descolonizador" latino-americanista; mas, este último, no interior do marxismo; e do gramscismo, obviamente, como modo específico de leitura marxista, ou seja, como filosofia da práxis, pensada como verdadeira "refundação" da tradição, como sugere Peter Thomas (2015, p. 104).

Creio, pois, que se podemos pensar com esses horizontes de dimensões amplas e inclusivas, de certo modo ousados e desafiadores, como nos sugere Ouviña, é porque, na América Latina, nos apropriamos do pensamento de Gramsci de modos de todo originais. Nesse sentido, o que proponho individuar retrospectiva e estrategicamente como escola latino-americana de hegemonia, dando conta da multidimensionalidade constitutiva das nossas realidades específicas, deverá apropriar-se, metodologicamente, do conceito gramsciano de tradutibilidade, vinculando-o aos procedimentos de mestiçagem, “antropofágicos”, mencionados acima: poderíamos denominá-la "tradutibilidade antropofágica".

\section{Duas polêmicas}

Uma das características fundamentais da escola latino-americana é que a sua identidade (assim como toda identidade, como é sabido) é marcada pelo jogo das relações que estabelece, pelos debates que a questionam, pelas teorias adversárias ou antagonistas que a colocam em discussão, pelos vários modos de ler Gramsci que são postos como alternativas, etc.

Nesse sentido, assinalamos o contraste desse escola nos confrontos com algumas abordagens teóricas, como a teoria leninista da re- 
volução, a teoria de dependência, com as suas variantes, as teorias nacional-populares e nacional-revolucionárias, as teorias sobre o populismo, a teologia e a filosofia da libertação, as várias teorias da democracia e da transição democrática que emergiram ao fim das ditaduras militares nos anos 1980; por fim, a partir dos anos 1990 e com peso maior na primeira década do século XXI, os Estudos subalternos e os Estudos Postcoloniais e Decoloniais. Nos últimos anos, os debates travados entre a escola latino-americana e a escola filológica italiana dos estudos gramscianos, suscitou, ainda, o problema da relação entre política e filologia, favorecendo um diálogo crítico cordial. Entre todos esses debates, considero pertinente discutir, brevemente, essas duas últimas visões.

\section{Um desafio teórico-político: a crítica "decolonial” de Walter Mignolo à recepção de Gramsci na América Latina}

Em 2012, Neelan Srivastava e Baidik Bhattacharya publicaram o controverso The Postcolonial Gramsci. No capítulo 9 do livro, intitulado Mariátegui and Gramsci in "Latin" America. Between Revolution and decoloniality, Walter Mignolo, semiólogo decolonialista argentino residente nos Estados Unidos, interpreta criticamente a recepção do pensamento de Gramsci na América Latina. As questões tratadas em seu artigo contrastam, imediatamente, com os elementos tratados no presente texto, e, ainda que seja impossível discuti-las amplamente aqui, considero necessárias, ao menos, algumas observações, a serem consideradas como notas para uma discussão mais ampla.

Antes de abordar os pontos controversos, gostaria de enfatizar minhas fortes simpatias teórico-políticas a respeito da ideia de "decolonialidade". A tensão teórica do conceito inverte a relação centro-periferia e produz um campo de forças oposto em relação às tendências colonializantes que marcam a relação Europa-não Europa, em termos econômicos, políticos, culturais e epistemológicos. Todavia, considero que a sua força se diminua quando utilizada em chave "provincial", muitas vezes reduzido a 
"pintar e celebrar a minha aldeia"; em outros termos, não para "pensar a minha aldeia em chave universal", no fluxo dos eventos globais, mas pensar daqui, por aqui e com os recursos daqui. Não pensar somando nossas posições - com o nosso olhar, as nossas teorias e visões de mundo, da nossa posição geográfica, cultural, econômica, política e epistemológica - aos movimentos críticos em relação ao norte imperialista eurocêntrico, de qualquer parte da periferia global, do "sul global", inclusive da Europa periférica etc., mas com uma pretensa pureza epistemológica que sonha fugir do passado colonial, das línguas dominantes, das influências culturais, das "ciências ocidentais" etc. Já vi, no Brasil, intelectuais de matriz marxista, latino-americanistas, que tentaram se fantasiar de "decolonialistas", com resultados infelizes, para dizer o mínimo.

Os fenômenos que questionamos são de caráter dúplice, globais e locais: "glocais", segundo o neologismo usado por Manuel Castells e outros pensadores da globalidade, e, por isso, requerem um tratamento complexo. Todavia, por trás de formas de pensamento complexo, muitas vezes o campo de forças culturais criticado como "colonização epistêmica" pela reflexão decolonial - baseada na reflexão seminal de Anibal Quijano (1992) - conseguiu impor as próprias marcas. A infinidade de ligações visíveis e invisíveis, resultado da conquista, do saque e do genocídio europeu pelo mundo, por meio do sangue, do fogo e da submissão cultural acabou sujeitando os povos do globo aos próprios projetos norte-imperialistas, fazendo com que até mesmo o pensamento crítico terminasse por ser reabsorvido nas suas tramas transformistas. É justamente à ação desse campo de forças, capaz de produzir o alinhamento das vontades aos propósitos de uma força dirigente, que Antonio Gramsci chamava de hegemonia ${ }^{19}$. Nesse sentido, renunciar à teoria da hegemonia em nome de uma posição decolonial não é apenas historicamente errado, mas é teórica e politicamente contraproducente. Ao mesmo tempo, a crítica decolonial se manifesta como um chamado a uma atenção permanente, como um alarme sensível quando se pensa a nossa posição no mundo. 
No texto de Mignolo, há numerosos temas que merece ser discutidos do ponto de vista da teoria de hegemonia. Da minha parte, gostaria, no limitado espaço à disposição, concentrar-me em alguns pontos cruciais: i) a tentativa espúria de se apropriar da figura de Mariátegui e Zavaleta Mercado; ii) a separação artificial entre o pensamento gramsciano e o pensamento nacional-popular; iii) a afırmação equivocada de que "Gramsci ingressou na América Latina a partir da Córdoba"; iv) a recusa de reconhecer o trabalho de Stuart Hall enquanto um pensador gramsciano "caribenho"20.

i) Segundo a leitura de Mignolo, na medida em que Mariátegui afronta a questão indígena, ele pode ser considerado o fundador da perspectiva decolonial, enquanto Gramsci teria sido incorporado e adaptado à realidade latino-americana pela esquerda eurocêntrica. Se, para Mariátegui, a questão central seria como enfrentar o "legado colonial”, para Gramsci consistiria em "como construir o socialismo", um projeto europeu.

A discussão é muito complexa; gostaria de fazer apenas duas observações. A primeira é que Mariátegui, longe de não considerar o problema do socialismo, o põe no centro de seu projeto estratégico; e, no centro do seu centro, a grande heresia: o socialismo indoamericano, centrado nos camponeses de origem indígena como sujeito histórico principal. No que concerne à segunda observação: Mignolo, neste texto, finge não conhecer o exaustivo trabalho de José Aricó sobre Mariátegui, em que o pensador argentino recupera a sua figura e a sua obra, evidenciando a relação crucial entre a difusão da obra de Gramsci e aquela de Mariátegui na América Latina: a já mencionada "difusão conectada".

A respeito do suposto distanciamento de Zavaleta Mercado do pensamento de Gramsci nos últimos anos da sua vida, os argumentos de Mignolo denotam a mesma fragilidade e incoerência. Por causa do limitado espaço do qual disponho, digo apenas - e sei muito bem que não se trata de um "argumento teórico" - que, na ocasião da conferência gramsciana de Asunción, no Paraguai ${ }^{21}$, discutindo a respeito 
dessa posição de Mignolo com Luis Tapia (o mesmo autor que Mignolo cita como fonte de suas referências a Zavaleta), o pensador boliviano comentou, com breves e cáusticas palavras - e, obviamente, de forma coloquial: se trata de "um delírio de Mignolo". O tema requer, certamente, um argumento sólido, em primeiro lugar, da parte de Mignolo ${ }^{22}$.

O problema parece residir no fato de que Mignolo, para fazer de Mariátegui e Zavaleta Mercado fundadores da sua própria posição, precisou forçar a distância destes autores em relação ao pensamento de Gramsci. O ponto teórico central é que Mignolo parece desconhecer o conceito de "tradutibilidade" de Cramsci, que se encontra na base do uso legítimo das categorias gramscianas na América Latina e da sua articulação com formas de pensamento autóctones, sem ser esse uso irremediavelmente condenado por "eurocentrismo" ou por qualquer outra forma de centralidade, como assinalei na discussão prévia acerca da relação entre o conceito de tradutibilidade de Cramsci e o projeto “antropofágico" de Andrade, ou a chamada à "mestiçagem", de Ouviña.

ii) No livro Los gramscianos argentinos. Cultura y política en la experiencia de Pasado y Presente (BURGOS, 2004), penso ter mostrado com bastante clareza a influência crucial de Gramsci sobre o campo da esquerda nacional-popular na Argentina, centrada na intervenção teórica de John William Cooke e de Horacio González; hoje existe uma importante bibliografia que mostra claramente essa relação (CÓMEZ, 2015; SERRA, 2019; DELLA ROCCA, 2014; CABEZAS, 2015, etc.). Em outros termos, a argumentação de Mignolo sobre a distância radical entre a "nova esquerda" (gramsciana) e a "esquerda nacional" (não gramsciana), não tem fundamento: movendo-se por percursos diversos, o pensamento de Gramsci vinculou-se de modo produtivo com as duas grandes correntes da nova esquerda argentina dos anos 1960 e 1970.

iii) Mignolo erra quando insiste no fato de que Gramsci teria entrado na América Latina "a partir de Córdoba" por meio da atividade do grupo "Pasado y Presente". "O fato de Gramsci ter entrada na Argentina a partir 
de Córdoba, e não de Buenos Aires, não foi um acaso", afırma Mignolo (2012, p. 209). Não apenas "não foi um acaso", mas simplesmente não ocorreu desse modo, não obstante a contribuição fundamental que o grupo liderado por José Aricó deu à sua difusão posterior. A difusão do pensamento gramsciano teve início, como demonstrado exaustivamente, com o trabalho do Partido Comunista Argentino, sob a direção da figura quase inclassificável de Héctor Pablo Agosti; esquecer-se disso cria não apenas uma grave confusão do ponto de vista historiográfıco, como simplifica sobremaneira a complexa trama da história de sua recepção. O erro histórico, que, por si mesmo, mereceria uma maior atenção, tende a ocultar a complexidade radical da recepção de seu pensamento, e deve, portanto, ser assinalado criticamente.

iv) Uma das posições mais desconcertantes é a recusa a considerar o trabalho de Stuart Hall enquanto "pensador caribenho". A finalização do texto de Mignolo dedicado às questões caribenhas, é surpreendente. O semiólogo argentino não vê nenhuma herança de Gramsci nas lutas e nas reflexões dos intelectuais afro-caribenhos jamaicanos - "muitos dos quais residentes nos Estados Unidos", diz Mignolo (2012, p. 203); “são todos 'fanonianos' antes que 'gramscianos'”: e isso porque, "para os intelectuais negros do Caribe, Gramsci não havia enfrentado as questões para eles mais relevantes" (MICNOLO, 2012, p. 203).

Portanto, se você está lutando pela descolonização e é um intelectual afro-caribenho (homem ou mulher), os problemas que enfrenta são significativamente diversos dos problemas que enfrentaria se você fosse um intelectual, homem ou mulher, "latino" americano, para o qual Cramsci era, e pode muito bem continuar a sê-lo, uma luz a guiar seus pensamentos e ações. Mas, lembre-se, há outras opções igualmente válidas. (MIGNOLO, 2012, p. 203).

Essas afırmações de Mignolo, além de parecer não considerar como "caribenha" a experiência de países como Cuba, Colômbia ou Venezuela (em cuja realidade é presente uma forte identidade caribenha), não levam em conta, obviamente de modo deliberado, as 
intervenções de um pensador "diaspórico" como Stuart Hall (nascido em 1932, na Jamaica, e emigrado para a Inglaterra em 1951, quando tinha 19 anos). Com efeito, como é possível escrever essas frases esquecendo-se, por exemplo, do já citado texto A relevância de Gramsci para os estudos de raça e etnicidade? Esse é, talvez, um ponto em que a "tradutibilidade antropofágica" da escola latino-americana da hegemonia nos permite, a título de exemplo, mostrar os limites da ideologia decolonial.

\section{O debate sobre filologia e política: o contraste entre a escola italiana e a escola latino-americana a partir dos anos 1980}

Uma outra experiência que nos permite identificar algumas características específicas da escola latino-americana é constituída pelo debate dos últimos anos entre estudiosos latino-americanos e italianos a respeito da relação entre filologia e política na difusão, estudo e discussão da herança gramsciana.

No encontro gramsciano decenal, ocorrido entre 18 e 20 de maio em Roma, no final da apresentação do texto escrito juntamente com Martín Cortés, expressamos publicamente o seguinte "mal-estar", como poderíamos chamá-lo:

Partimos da relação estreita entre teoria e política, que, como vimos, caracteriza o debate argentino, para nos interrogar-nos a respeito do debate italiano. Referimo-nos à percepção de um tipo de ruptura do nexo entre filosofia, historiografia, filologia e política. Todos fazemos referências ao nexo indissociável entre passado e presente, entre filosofia e política: falamos de práxis. Todavia, a reflexão sobre a atualidade teve um espaço menor em relação àquilo que pensamos que deveria haver hoje. Os estudos gramscianos italianos dos últimos anos deram resultados extraordinários no campo da análise filológica e da reflexão filosófica. Contudo, nos questionamos a respeito de como retornar à discussão sobre o nexo entre teoria e política. Não pretendemos uma intromissão no debate italiano, que, certamente, tem seus tempos e 
dinâmicas específıcas, como os temos todos. Partimos da exigência de estender o intercâmbio e o diálogo entre os gramscianos de todo o mundo, com a intenção de reforçar os nexos entre teoria e política. (CORTÉS; BURCOS, 2019, p. 464-465).

Na seção final da conferência (composta por Fabio Frosini, Guido Liguori e Giuseppe Vacca), na qual se tenta fazer um pequeno balanço do evento, emergiram algumas reações a essa "feliz provocação", como a definiu Giuseppe Vacca. Vejamos, brevemente, dois comentários.

De um lado, Guido Liguori assinala que, durante a conferência, emergiu:

[...] uma tensão positiva, entre aqueles que fazem pesquisa gramsciana na Itália e aqueles que o fazem fora da Itália [...] uma tensão entre aqueles que sublinhavam mais a importância da interpretação de Gramsci e aqueles que sublinhavam mais a importância, ou a necessidade, do uso de Gramsci. Para mim, interpretação e uso são duas coisas que devem andar a par e passo, devendo ser levadas adiante juntas, porque uma não se sustenta sem a outra, obviamente; não é gramsciano, me permito dizer.

De uma outra perspectiva, a intervenção de Giuseppe Vacca assinalou que:

[...] trinta anos depois [da conferência de Formia, 1989], é claro que Gramsci é estudado dentro de uma circulação internacional [...] E todos nós que estudamos Cramsci, não devemos deixar de ter constantemente em conta o modo como ele é estudado por todos os demais que o estudam no nível [...] dos estudos gramscianos internacionais [...]. São estudos conduzidos com o impulso de um enorme acúmulo de trabalho de "escolas" de pensamento que tem uma relação original, mais ou menos profunda, substantiva, intrínseca com Gramsci, e, assim, deram vida aos Estudos Culturais, aos Estudos Subalternos, Estudos Pós-coloniais, etc ${ }^{23}$. 
Aproveito as ressonâncias desta fala para afirmar que - além das escolas mencionadas por Vacca - existe na América Latina (possivelmente na invisibilidade do que é plenamente visível) uma verdadeira escola de pensamento sobre Gramsci, baseada em uma leitura particular da teoria da hegemonia.

O debate ocorrido em Roma teve importância particular para a explicitação dessa polêmica, mas gostaria de sublinhar o ponto de partida desse relativo distanciamento de perspectivas. Para o escopo de compreender o modo pelo qual os estudos gramscianos se desenvolveram na Itália, é significativo o comentário de Giuseppe Cospito contido na excelente introdução à vida e ao pensamento de Gramsci. Observando o contraste entre a enorme difusão dos escritos gramscianos em nível internacional e a respeito da sua (des)ventura em sua terra natal, escreve Cospito:

A extraordinária difusão internacional do pensamento de Gramsci ocorreu enquanto na Itália se verificava uma fase de relativo esquecimento, ligado ao declínio e ao posterior desaparecimento do Partido Comunista Italiano, o qual ele havia contribuído a fundar, e, na sequência, dirigido até a sua prisão. De resto, se, a partir do segundo pós-guerra, tinha sido justamente o seu próprio companheiro de lutas e sucessor, Palmiro Togliatti, que promoveu a publicação e a divulgação dos seus escritos, a sorte de Gramsci, continuando ligada àquela do partido, ainda depois do desaparecimento do Migliore [apelido dado a Togliati], era inevitável que seguisse, de algum modo, a fortuna do partido no período da sua crise definitiva. Esta circunstância, porém - analogamente ao que ocorreu, nos mesmos anos, relativamente a Marx -, permitiu, nos últimos decênios, um estudo finalmente livre de preocupações políticas imediatas e mais atento a historicizar e contextualizar a obras de Gramsci, também graças a um sempre maior conhecimento acerca das vicissitudes da sua biografia intelectual e política. (COSPITO, 2015, p. 6). 
Merece uma atenção particular a última frase da argumentação de Cospito; aquele estudo "finalmente livre de preocupações políticas imediatas" pavimentou a estrada para um trabalho filológico fenomenal sobre o material herdado, organizado em torno da denominada Edizione Nazionale degli scritti di Gramsci ${ }^{24}$, que produziu um tipo de revolução no âmbito dos estudos gramscianos. Essa enorme transformação teve início com a publicação da edição crítica dos Cadernos do cárcere, que inaugurou o tratamento filológico diacrônico dos textos, e que, no seu desenvolvimento, a partir das observações metodológicas de Gianni Francioni, teria conduzido a uma nova etapa. Se, como afırma Vacca (2016, p. 25): “o estudo diacrônico começou a produzir novas indagações que teriam tornado crescentemente inutilizável toda a literatura gramsciana precedente", poder-se-ia dizer que os novos estudos filológicos dos anos $1990^{25}$ produziram um verdadeiro enveIhecimento em massa das interpretações anteriores.

Considero, entretanto, que tais conquistas de natureza científica também produziram uma consequência indesejada: o exagerado afastamento da política. Se, por um lado, o trabalho científico conseguiu unir os esforços teóricos dos estudiosos gramscianos, evitando, temporariamente, os confrontos políticos que a realidade efetiva da política italiana colocara à porta da ciência filológica - ou seja, um trabalho teórico "livre de preocupações políticas imediatas", retomando a precisa afirmação de Cospito -, por outro lado, a meu juízo, poderia ter criado um certo desequilíbrio entre o fluxo das análises filológicas e o fluxo da análise e da intervenção política. Esta complexidade configura, em todo caso, uma característica específica daquela que poderíamos chamar de escola filológica italiana de estudos gramscianos ${ }^{26}$.

Como tentei mostrar neste artigo, a escola latino-americana é composta por diversas "correntes" que se intercruzam em um conjunto de “interpretações-usos”. Como já mencionado, a relação ativa, o seu entrelaçamento com a política, não impediu ao gramscis- 
mo latino-americano de produzir uma reflexão teórica de alto nível. Talvez fosse correto afirmar o contrário.

Gramsci, no seu dramático percurso de reflexão realizado na solidão do cárcere, representou a culminância de um longo e árduo processo de absorção-reelaboração, por parte do proletariado moderno, dos expoentes máximos da tradição crítica europeia (a classe operária como "herdeira da filosofia clássica alemã"), transformando-se, ao mesmo tempo, em matriz para novas expansões, absorções e reelaborações que são desenvolvidas no interior de diversas escolas de pensamento surgidas na esteira do filósofo da práxis italiano: Estudos Gramscianos, Estudos Culturais, Estudos Subalternos, Estudos Pós-coloniais, Estudos Decoloniais, os estudos "Arrighianos" e Neo-Gramscianos nas Relações Internacionais, a Teoria Política do Discurso de Ernesto Laclau e Chantal Mouffe (conhecida também como "Escola de Essex"), a Teoria do Populismo de Laclau, a Teoria da Democracia Agonista de Mouffe etc. Nesta listagem deveria ser incluída também, se minhas conclusões estão mais ou menos corretas, a escola latino-americana da hegemonia, que tentei descrever neste texto.

Da descrição realizada, poder-se-á objetar que todo esse cruzamento de autores e temáticas, essa mestiçagem, pela sua própria natureza mista, não pode formar uma "escola”. No entanto, o contrário também pode ser verdadeiro: poderia representar um perfeito exemplo de "escola gramsciana", em que teoria e práxis política se interpenetram integralmente, como "filosofia vivente". A história nos dirá.

\section{Referências}

ABREU, Marina Maciel. Serviço Social e a organização da cultura: perfis pedagógicos da prática profissional. 1. ed. São Paulo: Cortez, 2002.

ACGIO, Alberto (Org.). Gramsci. A vitalidade de um pensamento. São Paulo: Editora Unesp, 1998.

ACOSTI, Héctor Pablo. Echeverría. Buenos Aires: Futuro, 1951. 
ALIACA, Luciana. Gramsci e Pareto. Ciência, história e revolução. Curitiba: Appris, 2017.

ALTMAN, Breno. Venezuela e Gramsci. Blog de Luíz Müller, 2017. Disponível em: https://luizmuller.com/2017/08/29/venezuela-e-gramsci-por-breno-altman/ ANDRADE, Oswald de [José Oswald do Sousa Andrade]. Esquema ao Tristão de Athayde. Revista de Antropofagia, n²/5, p. 3, 1929.

ANDRADE, Oswald de [José Oswald do Sousa Andrade]. Obras Completas, Vol. VI: do Pau-Brasil à Antropofagia e às Utopias. Manifestos, teses de concursos e ensaios. 2. ed. Rio de Janeiro: Civilização Brasileira, 1978.

ARECO, Sabrina. A filologia vivente de A. Cramsci. Revista Mediações, v. 24, n. 1, p. 209-227, 2019.

ARICÓ, José M. Dilemas del marxismo en América Latina. Antología esencial. Comp. y ed. por M. Cortés. Buenos Aires: CLACSO - Fundación Rosa Luxemburgo, 2018. Disponivel em: http://biblioteca.clacso.edu.ar/clacso/ se/20171117024109/Antologia_Jose_Arico.pdf

ARICÓ, José M. Mariátegui y los orígenes del marxismo latino-americano. Segunda edición corregida y aumentada. México D.F.: Ed. Pasado y Presente, 1980.

ARICÓ, José M. Prólogo. In: J. LABASTIDA MARTIN DEL CAMPO (A cura di). Hegemonía y alternativas políticas en América Latina. México D.F.: Siglo XXI, 1985, pp. 11-16.

ARRUDA JÚNIOR, Edmundo de Lima de. Gramsci e o direito. Reflexões sobre novas juridici-dades. In: ARRUDA JÚNIOR, E. L.; BORGES FILHO, N. (Eds.). Gramsci. Estado, direito e socie-dade. Florianópolis: Letras Contemporâneas, p. 27- 42, 1995.

BALSA, Javier. Ernesto Laclau e l'egemonia: concetti chiave e dialoghi con Gramsci. In: FROSINI, Fabio; GIASI, Francesco (A cura di). Egemonia e Modernità. Gramsci in Italia e nella cultura internazionale. Roma: Viella, 2019a, pp. 467-83.

BALSA, Javier. Filología y política en la discusión contemporánea de la teoría de la hegemo-nía. In: CENTRO DE ESTUDIOS GERMINAL (Org.). Gramsci, la teoría de la hegemonía y las transformaciones políticas recientes en América Latina. Actas del Simposio Internacional Asunción, 27-28/8/2019, 1a edición, Asunción, Centro de Estudios Germinal, 2019b, pp. 11-36. Disponível em: http://germinal.pyglobal.com/libros/gramsci_simposio.pdf 
BALSA, Javier. Las tres lógicas de la construcción de la hegemonía. Revista Theomai, n. 14, 2006. Disponivel em: http://www.revista-theomai.unq.edu. ar/numero14/ArtBalsa.pdf

BARBERO, Juan J. Introducción. In: COSPITO, G. El ritmo del pensamiento. Una lectura diacrónica de los "Cuadernos de la cárcel". Buenos Aires: Continente, 2016.

BARBOSA, Jefferson Rodrigues. Chauvinismo e extrema direita. Crítica aos herdeiros do sigma. São Paulo: Unesp, 2015b.

BARBOSA, Jefferson Rodrigues. Gramsci a crítica ao Fascismo. In: VIII Colóquio Marx e Engels, 2015, Campinas. Anais do VIII Colóquio Marx e Engels, Vol. 1, 2015a.

BIANCHI, Alvaro. Gramsci in Brasile. In: KANOUSSI, Dora; SCHIRRU, Giancarlo; VACCA, Giuseppe (A cura di). Studi gramsciani nel mondo. Gramsci in America Latina. Bologna: il Mulino, 2011.

BIANCHI, Alvaro. O laboratório de Gramsci. Filosofia, história e política. São Paulo: Alameda, 2008.

BIANCHI, Alvaro; MUSSI, Daniela; ARECO, Sabrina (Org.). Filologia e política. Porto Alegre: Zouk, 2019.

BURCOS Raúl. Los gramscianos argentinos. Cultura y política en la experiencia de Pasado y Presente. Buenos aires: Siglo XXI de España Editores / Siglo XXI de Argentina Editores, 2004.

BURGOS, Raúl. El concepto de objetividad en Gramsci. Tempo Social - Revista de sociologia da USP, São Paulo, v. 31, n. 2, pp. 95-121, 2019a. Disponível em: http://www.revistas.usp.br/ts/article/view/157686

BURCOS, Raúl. O conceito de Classe(s) subalterna(s) na trama conceitual da teoria gramsciana da hegemonia. Uma reflexão a partir da América Latina. In: BIANCHI, Alvaro; MUSSI, Daniela; ARECO, Sabrina (Org.). Filologia e política. Porto Alegre: Zouk, 2019b, p.191-229.

CABEZAS, Oscar Ariel (Comp.). Gramsci en las orillas. La Cebra: Adrogué, 2015. CALELLO, Hugo; NEUHAUS, Susana (Comp.). El fantasma socialista y los mitos hegemónicos. Gramsci y Benjamin en América Latina. Buenos Aires: Herramienta, 2010.

CAMPIONE, Daniel. Para leer a Gramsci. Buenos Aires: Ediciones del CCC, 2007. 
CARLUCCI, Alessandro. Gramsci and Languages. Unification, Diversity, Hegemony. Leiden-Boston: Brill, 2013.

CENTRO DE ESTUDIOS GERMINAL (Org.). Gramsci, la teoría de la hegemonía y las transformaciones políticas recientes en América Latina. Actas del Simposio Internacional Asunción, 27-28/8/2019, 1a edición, Asunción, Centro de Estudios Germinal, 2019. Disponivel em: http://germinal.pyglobal.com/ libros/gramsci_simposio.pdf

CHABALGOITY, Diego. O estudo da Ontologia do oprimido do simples entrelaçamento de correntes filosóficas à tradutibilidade Gramsciana e decolonial. In: LOLE, Ana (Org.). O fermento de Cramsci na nossa filosofia, política e educação. Rio de Janeiro: Mórula, 2018.

CIENFUECOS, Fermán. La República Democrática. Managua: Roque Dalton, 1986.

COIMBRA, Eric Araujo Dias. Duas estrelas e dois projetos de hegemonia: a influência do pensamento de Gramsci no partido dos trabalhadores (bra) e no bloco de esquerda (por). Tese de doutorado, Universidade Federal de Santa Catarina, Florianópolis, 2017.

CONCHEIRO BÓRQUEZ, Elvira. Gramsci en América Latina. In: MODONESI, M. (Coord.). Horizontes gramscianos. Estudios en torno al pensamiento de Antonio Gramsci. México D.F.: UNAM, 2013.

COOKE, John William. Aportes a la crítica del reformismo en la Argentina. Pasado y Presente, Segunda época, n²-3, 1973.

CÓRDOVA, Arnaldo. Antonio Gramsci e a esquerda mexicana. In: COUTI$\mathrm{NHO}$, Carlos Nelson; NOGUEIRA, Marcos Aurelio (Org.). Gramsci e a América Latina. Rio de Janeiro: Paz e Terra, 1988, p. 85-101.

CORTÉS, Martín. Un nuevo marxismo para América Latina. José Aricó: traductor, editor, intelectual. Buenos Aires: Siglo XXI, 2015.

CORTÉS, Martín; BURGOS, Raúl. Le eredità di Gramsci in Argentina. In: FROSINI, Fabio; CIASI, Francesco (A cura di). Egemonia e Modernità. Gramsci in Italia e nella cultura internazionale. Roma: Viella, 2019, pp. 447-65.

CORTIZO, María Del Carmen. Administração de justiça e construção de hegemonia. Revista Katalysis, Florianópolis, v. 9, n. 1, p. 99-106, 2006.

COSPITO, Giuseppe. II ritmo del pensiero. Per una lettura diacronica dei "Quaderni del carcere" di Gramsci. Napoli: Bibliopolis, 2011.

COSPITO, Giuseppe. Introduzione a Gramsci. Genova: il nuovo melangolo, 2015. 
COUTINHO, Carlos Nelson. Gramsci en Brasil. In: CABEZAS, Oscar Ariel (Comp.). Gramsci en las orillas. La Cebra: Adrogué, 2015, pp. 283-309 (1 ed. 1986).

COUTINHO, Carlos Nelson. Gramsci. Um estudo sobre seu pensamento político. Rio de Janeiro: Civilização Brasileira, 1999. (1 ed. 1981).

COUTINHO, Carlos Nelson; NOGUEIRA, Marcos Aurelio (Org.). Gramsci e a América Latina. Rio de Janeiro: Paz e Terra, 1988.

D'ORSI, Angelo. Gramsci. Una nuova biografia. Milano: Feltrinelli, 2017.

DAGNINO, Evelina (Org.). Sociedade civil e espaços públicos no Brasil. São Paulo: Paz e Terra, 2002.

DAL MASO, Juan. El marxismo de Gramsci. Notas de lectura sobre los Cuadernos de la cárcel. Buenos Aires: Ediciones IPS, 2016.

DAL MASO, Juan. Hegemonía y lucha de clases. Tres ensayos sobre Trotsky, Gramsci y el marxismo. Buenos Aires: Ediciones IPS, 2018.

DE CARVALHO, Alba Maria P. A teoria gramsciana da transformação social. In: A questão da transformação e o trabalho social. São Paulo: Cortez, 1982.

DEL ROIO, Marcos. Gramsci e a emancipação do subalterno. São Paulo: Editora Unesp, 2018.

DEL ROIO, Marcos. Os prismas de Gramsci. A fórmula política da frente única (1919-1926). São Paulo: Xamã, 2005.

DELLA ROCCA, Mario. Gramsci en la Argentina. Los desafíos del kirschnerismo. Buenos Aires: Dunken, 2014.

DIAS, Edmundo Fernandes et. al. (Org.). O outro Gramsci. São Paulo: Xamã, 1996.

DIAS, Edmundo Fernandes. Gramsci em Turim. A construção do conceito de hegemonia. São Paulo: Xamã, 2000.

DIAS, Edmundo Fernandes. Revolução passiva e modo de vida: ensaios sobre as classes subalternas, o capitalismo e a hegemonia. São Paulo: Editora José Luís e Rosa Sundermann, 2012.

DURICUETTO, Maria Lúcia. Sociedade civil e democracia. Um debate necessário. São Paulo: Cortez, 2007.

EDITORIAL POPULAR LA PAJARILLA. Parágrafos sobre la filosofía de la praxis. Selección de notas de los cuadernos de la cárcel de Antonio Gramsci. Santiago de Chile: La pajarilla, 2020. 
ESTEVA, Rosario; PARODI, Rosario (Comp.). Gramsci: los intelectuales y la sociedad actual. Habana: Centro de desarrollo e investigación de la Cultura Cubana Juan Marinello, 2006.

ESTEVA, Rosario; PARODI, Rosario (Comp.). Hablar de Gramsci. Habana: Centro de desarrollo e investigación de la Cultura Cubana Juan Marinello, 2003.

FERNÁNDEZ DÍAZ, Osvaldo. Selección y Prólogo. Antonio Gramsci. Maquiavelo Y Lenin. Notas para una Teoría Política Marxista. Santiago de Chile: Editorial Popular La Pajarilla, 2020. 1 Ed.: Santiago: Editorial Nascimiento, 1971]

FERNÁNDEZ DÍAZ, Osvaldo; OSSANDÓN VÉLIZ, Gonzalo. Antonio Gramsci y su laberinto. San-tiago de Chile: La Pajarilla, 2020.

FILIPPI, Alberto. Gramsci en nuestra américa a los ochenta años de su muerte: debates y reflexiones actuales sobre sociedad civil, hegemonía e instituciones jurídico-políticas. Estudios Sociales, n. 53, julio-diciembre, pp. 69-92, 2017.

FOLLIE, Attilio. Hugo Chavez parla di Antonio Gramsci. In: Blog di Attilio Follie, 3 giugno 2007. Disponivel em: https://umbvrei. blogspot.com/2007/06/hugo-chavez-parla-di-antonio-gramsci.html

FONTES, Virgínia. Gramsci, Estado e sociedade civil: anjos, demônios ou lutas de classes? Outubro, n. 31, $2^{\circ}$ sem. 2018.

FRESU, Gianni. Nas Trincheiras do ocidente. São Paulo: Editora Unesp, 2017.

FROSINI, Fabio. La religione dell'uomo moderno. Politica e verità nei "Quaderni del carcere" di Antonio Gramsci. Roma: Carocci, 2010.

FROSINI, Fabio. Le tensioni dell'egemonia: Los usos de Gramsci di Juan Carlos Portantiero. Filosofia Italiana, XII, n. 2, pp. 105-128, 2017.

FROSINI, Fabio. Sulla "traducibilità" nei "Quaderni” di Gramsci. Critica Marxista, n.s., n. 6, pp. 29-38, 2003.

FROSINI, Fabio. Traducibilità dei linguaggi e filosofia della praxis: su una fonte crociana dei «Quaderni». Critica Marxista, n.s., n. 6, pp. 39-48, 2016.

FROSINI, Fabio. Traducibilità dei linguaggi e unità di teoria e pratica nei "Quaderni del carce-re" di Antonio Cramsci. In: PASQUINI, L.; ZANELLI, P. (A cura di). Crisi e critica della modernità nei "Quaderni del carcere" di Antonio Cramsci. Milano: Mimesis, 2019.

FROSINI, Fabio; CIASI, Francesco (A cura di). Egemonia e Modernità. Gramsci in Italia e nella cultura internazionale. Roma: Viella, 2019. 
FUENTES, Diana. El lenguaje como espacio de pugna y de superación del sentido común. Materialismo Storico, n. 2, vol. V, pp. 188-211, 2018.

FUENTES, Diana; MODONESI, Massimo (Coords.). Gramsci en México. Ciudad de México: Universidad Autónoma Metropolitana-Xochimilco, 2020.

CALASTRI, Leandro de Oliveira. A violência política no pensamento de Antonio Gramsci (Quaderni del carcere: 1929-1935). Revista de Ciências Sociais (UFC), v. 50, pp. 257-289, 2019.

GANTIVA, Jorge. Gramsci, América Latina y los intelectuales. Aquelarre. Revista del Centro Cultural Universitario, v. 9, n. 19, pp. 115-128, 2010.

CARCÍA CANCLINI, Néstor. Cultura y organización popular: Gramsci con Bourdieu. Cuadernos políticos, n. 39, pp. 75-82, 1984.

GARCÍA LINERA, Álvaro. A potência plebeia. Ação coletiva e identidades indígenas, operárias e populares na Bolívia. São Paulo: Boitempo, 2010.

GARCÍA LINERA, Álvaro. Gramsci en Bolivia: del estado aparente al estado integral. In: CABEZAS, Oscar Ariel (Comp.). Gramsci en las orillas. La Cebra: Adrogué, 2015, pp. 311-31.

GILLER, Diego Martín. René Zavaleta Mercado. Una revolución contra Bolívar. Los Polvorines: Universidad Nacional de Sarmiento, 2016.

GILLER, Diego Martín; OUVIÑA, Hernán. René Zavaleta Mercado. Pensamiento crítico y marxismo abigarrado. Santiago de Chile: Quimantú, 2016.

GIORDANI, Jorge. Gramsci, Italia y Venezuela: apuntes e impresiones. Caracas: Vadell Hermanos Editores, 2009.

GÓES, Camila. Repensando a subalternidade: de Antonio Gramsci à teoria pós-colonial. Outubro, n. 26, pp. 91-111, 2016.

COMES, Victor Leandro Chaves. Por que os homens não se rebelam? Aquiescência e política em Antonio Gramsci. Rio de Janeiro: Letra Capital, 2015.

GÓMEZ, Sebastián. La recepción y usos de Antonio Cramsci en el nacionalismo popular pedagógico y la nueva izquierda pedagógica, 19591976. Tesi di dottorato, Universidad Nacional de Buenos Aires, Buenos Aires, 2015.

GONZÁLEZ, Horacio. De los encarcelados al "libro viviente" de Gramsci. In: CABEZAS, Oscar Ariel (Comp.). Gramsci en las orillas. La Cebra: Adrogué, 2015, pp. 45-61. 
GONZÁLEZ, Horacio. Para nosotros, Antonio Gramsci, prefazione. In: GRAMSCl, A. El príncipe moderno y la voluntad nacional-popular. Buenos Aires: Puentealsina, 1971.

GUIBAL, Francis. Gramsci, filosofía, política, cultura. Lima: Tarea, 1981.

HALL, Stuart. A relevância de Gramsci para os estudos de raça e etnicidade. In: Da diáspora. Identidade e mediações culturais. Belo Horizonte: Editora da UFMG, 2009 [1 ed. Inglês: Gramsci's relevance for the study of Race and Ethnicity. Journal of Communication Inquiry, v. 10, n. 2, 1986, pp. 5-27].

HALL, Stuart. Gramsci and Us. Marxism Today, June, pp. 16-21, 1987.

HERRERA ZCAIB, Miguel Ángel. Antonio Gramsci y el pensamiento de ruptura. Bogotá: Universidad Nacional de Colombia, 2015.

HIDALGO FLOR, Francisco. Los movimientos indígenas y la lucha por la hegemonía: el caso de Ecuador. Buenos Aires: CLACSO, 2005. Disponível em: http:// bibliotecavirtual.clacso.org.ar/clacso/gt/20101026013037/15HidalgoFlor.pdf

IBAÑEZ, Alfonso. Gramsci y Mariátegui: la recreación del marxismo revolucionario. Lima: Tarea, 1979.

IVES, Peter; LACORTE, Rocco (Eds.). Gramsci, language, and translation. Lanham: Lexington Books, 2010.

KANOUSSI, Dora. Gramsci in Messico. In: KANOUSSI, Dora; SCHIRRU, Giancarlo; VACCA, Giuseppe (A cura di). Studi gramsciani nel mondo. Gramsci in America Latina. Bologna: il Mulino, 2011a.

KANOUSSI, Dora. La traducibilità dei linguaggi nei Quaderni del carcere. In: KANOUSSI, Dora; SCHIRRU, Giancarlo; VACCA, Giuseppe (A cura di). Studi gramsciani nel mondo. Gramsci in America Latina. Bologna: il Mulino, 2011b.

KANOUSSI, Dora; MENA, Javier. La revolución pasiva: una lectura a los cuadernos de la cárcel. Puebla: Universidad Autónoma de Puebla, 1985.

KANOUSSI, Dora; SCHIRRU, Giancarlo; VACCA, Giuseppe (A cura di). Studi gramsciani nel mondo. Gramsci in America Latina. Bologna: il Mulino, 2011.

KAYSEL, André. Caminhos cruzados: marxismo e nacionalismo no Brasil e no Peru (1928-1964). Lua Nova, n¹06, pp. 247-275, 2019.

KOHAN, Néstor. Héctor P. Agosti, introductor de Gramsci en América Latina. Gramsci e o Brasil, 2004. Disponível em: http://www.acessa.com/ grams$\mathrm{ci} /$ ?page= $=$ isualizar\&id $=165$. 
LACLAU, Ernesto; MOUFFE, Chantal. Hegemonia e estratégia socialista. Por uma política democrática radical. São Paulo/Brasília: Intermeios/CNPq, 2015. (1 ed. 1985).

LACORTE, Rocco. "Espressione" e "traducibilità" nei "Quaderni del carcere". In DURANTE, Lea; LIGUORI, Guido (A cura di). Domande dal presente. Studi su Gramsci, Roma: Carocci, 2012, pp. 109-21.

LACORTE, Rocco. Sobre alguns aspectos da "tradutibilidade" nos Cadernos do cárcere de Antonio Gramsci e algumas das suas implicações. Educação e Filosofia, v. 28, n. 55, pp. 59-98, 2014.

LACORTE, Rocco. Translatability, language and freedom in Gramsci's "Prison Notebooks". In: IVES, Peter; LACORTE, Rocco (Eds.). Gramsci, language, and translation. Lanham: Lexington Books, 2010, p. 213-24.

LAHUERTA, Milton. Gramsci e os intelectuais: entre clérigos, populistas e revolucionários. In: ACGIO, Alberto (Org.). Gramsci. A vitalidade de um pensamento. São Paulo: Editora Unesp, 1998, pp. 133-60.

LÉVANO, César. Gramsci y Mariátegui. In: Regionalismo y Centralismo. Lima: Amauta, 1979.

LICUORI, Guido; VOZA, Pasquale (A cura di). Dizionario Gramsciano. 19261937. Roma: Carocci,2009. [Edição Brasileira, Boitempo, 2017]

LOLE, Ana (Org.). O fermento de Cramsci na nossa filosofia, política e educação. Rio de Janeiro: Mórula, 2018.

LÓPEZ, María Pia. Izquierdas: La lengua como legado y crítica. In: CABEZAS, Oscar Ariel (Comp.). Gramsci en las orillas. La Cebra: Adrogué, 2015, pp. 15-30.

MAIRA, Antonio. Hugo Chávez presenta a Gramsci ante cientos de miles de personas. Cuba debate, 10 junio 2007. Disponivel em: http://www.cubadebate.cu/opinion/2007/06/10/hugo-chavez-presenta-a-gramsci-antecientos-de-miles-de-personas/\#.Xht-dyNrxPY

MARIÁTECUI, José Carlos. Siete ensayos de interpretación de la realidad peruana, Lima: Amauta, 1987. (1ª ed. 1928).

MARTÍNEZ-HEREDIA, Fernando. Gramsci en la Cuba de los años Sesenta. In: MARTÍNEZ-HEREDIA, Fernando. Pensar en tiempo de Revolución: antología esencial. Comp. por M. Sán-chez Quiróz, Buenos Aires: CLACSO, 2018, pp. 177-90 (1 ed. 2003). Disponível em: http://biblioteca.clacso.edu.ar/clacso/ se/20180524041744/Antologia_Fernando_Martinez_ Heredia.pdf 
MARTÍNEZ-HEREDIA, Fernando. Gramsci nella Cuba degli anni Sessanta. In: KANOUSSI, Dora; SCHIRRU, Giancarlo; VACCA, Giuseppe (A cura di). Studi gramsciani nel mondo. Cramsci in America Latina. Bologna: il Mulino, 2011.

MARTINS, Marcos Francisco. Marx, Gramsci e o conhecimento. Campinas: Autores associados; Americana: Unisal, 2008.

MASSARDO, Jaime. A proposito dell'itinerario di Cramsci in Cile, in KANOUSSI, Dora; SCHIRRU, Giancarlo; VACCA, Giuseppe (A cura di). Studi gramsciani nel mondo. Gramsci in America Latina. Bologna: il Mulino, 2011.

MAZZEO, Miguel. Introducción al poder popular. El sueño de una cosa. Santiago de Chile: Tiempo Robado, 2014. (1 ed. El Colectivo, Buenos Aires, 2006).

MEDRANO, Juan Ramón. Revolución democrática. Tesis para la estrategia del FMLN. Estudios Centroamericanos Eca, n. 527, pp. 723-39, 1992.

MELIS, Antonio. Mariátegui, el primer marxista de América. In: Mariátegui y los orígenes del marxismo latino-americano. Cuadernos de "Pasado y Presente", n60, 1978. (1 ed. 1967).

MENA, Javier; KANOUSSI, Dora. La revolución pasiva: una lectura de los Cuadernos de la cárcel. Puebla: Universidad Autónoma de Puebla, 1985.

MICNOLO, Walter. "Mariátegui and Cramsci in 'Latin' America. Between Revolution and decoloniality". Em: Neelan Srivastava e Baidik Bhattacharya (Eds.) The Postcolonial Gramsci. New York: Routledge, 2012)

MILITÃO, Maria Socorro Ramos. Crise orgânica, hegemonia e revolução passiva gramsciana. Revista Ideação, v. 1, p. 20-34, 2019.

MODONESI, Massimo. Usos del concepto gramsciano de revolución pasiva en América Lati-na. Observatorio latino-americano y caribeño, n. 1, pp. 51-79, 2017.

MUSSI, Daniela. Política e literatura: Antonio Gramsci e a crítica italiana. São Paulo: Alameda, 2014.

NASCIMENTO, Adriano; LEITE, Josimeire de Omena (Org.). Gramsci em perspectiva. Maceió: Edufal, 2017.

NERES, Geraldo Magella. Cramsci e o "moderno príncipe": a teoria do partido nos Cadernos do Cárcere. São Paulo: Cultura Acadêmica, 2012.

NOGUEIRA, Marco Aurélio. Gramsci, a questão democrática e a esquerda no Brasil. In: COUTINHO, Carlos Nelson; NOGUEIRA, Marcos Aurelio (Org.). Gramsci e a América Latina. Rio de Janeiro: Paz e Terra, 1988, p. 129-152. 
NOGUEIRA, Marco Aurelio. Um Estado para a sociedade civil. Temas éticos e políticos da gestão democrática. São Paulo: Cortez, 2004.

NOSELLA, Paolo. A escola de Gramsci. 3 ed. São Paulo: Cortez, 2004.

NUN, José. Marginalidad y exclusión social. Buenos Aires: Fondo de cultura económica, 2001. (1 ed. Superpoblación relativa, ejército industrial de reserva y masa marginal. Revista Latino-americana de Sociología, v. 5, n. 2, pp. 178-236, julio 1969).

OLIVEIRA, Francisco de; BRAGA, Ruy; RIZEK, Cibele (Org.). Hegemonia às avessas. Economia, política e cultura na era da servidão financeira. São Paulo: Boitempo, 2010.

OLIVER COSTILLA, Lucio. Conflictos y tensiones en torno del Estado ampliado en América Latina: Brasil y México entre la crisis orgánica del Estado y el problema de la hegemonía. In: América Latina. Los derechos y las prácticas ciudadanas a la luz de los movimientos Popula-res. Buenos Aires: CLACSO, 2009, pp. 51-79.

ORTEGA REYNA, Jaime. Gramsci en México: Tres momentos para una nueva gramática de la política. In: CABEZAS, Oscar Ariel (Comp.). Gramsci en las orillas. La Cebra: Adrogué, 2015, pp. 237-57.

ORTIZ, Santiago. ¿Por qué Gramsci no llegó a Ecuador?. In: La línea de Fuego, 2018. Disponível em: https://lalineadefuego.info/2018/05/15/por-que-gramsci-no-llego-a-ecuador-por-santiago-ortiz/

OUVIÑA, Hernán. Indigenizar el marxismo. Apuntes para descolonizar los proyectos emancipatorios. In: Gramsci en América Latina, 2017. Disponível em: https:// gramscilatinoamerica.wordpress.com/2017/10/12/indigenizar-el- marxismo/.

OUVIÑA, Hernán. René Zavaleta, frecuentador de Gramsci. In: GILLER, D.; OUVIÑA, H. (Comp.). René Zavaleta Mercado. Pensamiento crítico y marxismo abigarrado. Santiago de Chile: Editorial Quimantú, 2016.

PARIS, Robert. Mariátegui y Gramsci: prolegómenos a un estudio contrastado de la difusión del marxismo. Socialismo y Participación, n. 23, 1983.

PASSOS, Rodrigo Duarte Fernandes dos. Gramsci e a teoria crítica das relações internacionais. Novos Rumos, v. 50, n. 2, p. 1-19, 2013.

POMAR, Wladimir. A questão do socialismo - II. Correio da cidadania, 30/4/2019. Disponível em: http://www.correiocidadania. com.br/colunistas/ wladimir-pomar/13748-a-questao-do-socialismo-ii 
PORTANTIERO, Juan Carlos, 1980. Gramsci para latino-americanos. In: SIRVENT, Carlos (Coord.). Gramsci y la política. México D.F.: UNAM, 1980, pp. 29-51.

PORTANTIERO, Juan Carlos. Los usos de Gramsci. In: GRAMSCI, A. Escritos políticos (1917-1933), Cuadernos de "Pasado y Presente, n 54, 1977.

QUIJANO, Anibal. Colonialidad y modernidad/racionalidad. Perú Indígena, v. 13, n. 29, pp. 11-20, 1992.

RAMOS, Leonardo César Souza. Hegemonia, Revolução Passiva e Clobalização: o Sistema G7/8. Belo Horizonte: Editora PUC Minas, 2013.

RAPONE, Leonardo. El joven Gramsci. Cinco años que parecen siglos (19141919). Rosario: Prohistoria Ediciones, 2019.

REIS, Claudio. O nacional popular em Antonio Gramsci: um projeto de nação das classes trabalhadoras. Curitiba: Appris, 2020.

RICUPERO, Bernardo. Antonio Gramsci e Oswald de Andrade: ou tradução e antropofagia. In: BIANCHI, Alvaro; MUSSI, Daniela; ARECO, Sabrina (Org.). Filologia e política. Porto Alegre: Zouk, 2019, pp. 155-64.

RICUPERO, Bernardo. O “original" e a "cópia” na Antropofagia. Sociologia \& Antropologia, v. 8, n. 3, pp. 875-912, 2018. Disponivel em: http://www.sociologiaeantropologia.com.br/wp-content/uploads/2018/10/v08nO3_completa.pdf

RODRÍCUEZ-RINCÓN, Yolanda; MORA LEMUS, Giovanni. Antonio Gramsci. Subjetividades y saberes sociales. Bogotá: Universidad Nacional de Colombia, 2016.

ROSÁLIO SILVA, Deise. Senso comum, ideologia e filosofia na constituição de conhecimento, consciência e prática política. Materialismo Storico, n. 2, v. V, pp. 267-90, 2018.

ROVELLI, José Gabriel. Una “fantasía concreta”. El mito político en los escritos de Antonio Gramsci. Materialismo Storico, n. 2, v. V, pp. 291-305, 2018.

SADER, Emir. Gramsci. Poder, política e partido. São Paulo: Expressão Popular, 2005.

SALLES, Ricardo. Gramsci para historiadores. Revista História da Historiografia, n. 10, pp. 211-28, 2012.

SAVIANI, Dermeval. Educação: do senso comum à consciência filosófica. 18 ed. Campinas: Autores Associados, 2009. (1 ed. 1980).

SCHIRRU, Giancarlo. La categoria di egemonia e il pensiero linguistico di Antonio Gramsci. In D'ORSI, A. (A cura di). Egemonie. Napoli: Dante \& Descartes, 2008. 
SCHLESENER, Anita Helena. A escola de Leonardo: política e educação nos escritos de Gramsci. Brasília: Liber Livro, 2009.

SCHLESENER, Anita Helena. Grilhões invisíveis: As dimensões da ideologia, as condições de subalternidade e a educação em Gramsci. Ponta Grossa: Ed. UEPG, 2016.

SCHLESENER, Anita Helena. Revolução e cultura em Gramsci. Curitiba: Ed. UFPR, 2001. SECCO, Lincoln. Gramsci e o Brasil: recepção e difusão de suas ideias. São Paulo: Cortez, 2002.

SEMERARO, Giovanni. Gramsci e os novos embates da filosofia da práxis. Aparecida (S.P.): Ideias \& Letras, 2006.

SEMERARO, Giovanni. Libertação e hegemonia. Realizar a América Latina pelos movimentos populares. Aparecida (S.P.): Ideias \& Letras, 2009.

SERRA, Pasquale. El populismo argentino. Buenos Aires: Prometeo, 2019.

SILVA, Marcos Aurélio. Dialética e geografia em Antonio Gramsci. Lutas Sociais, v. 17, n. 31, pp. 21-32, 2013.

SIMIONATTO, Ivete, 2004. Gramsci. Sua teoria, incidência no Brasil, influência no Serviço Social. Florianópolis/São Paulo: Ed. da UFSC/Cortez, 2004. (1 ed. 1995).

SIMIONATTO, Ivete. Recepção e difusão das ideias de Gramsci no Brasil: tendências e perspectivas. In: BIANCHI, Alvaro; MUSSI, Daniela; ARECO, Sabrina (Org.). Filologia e política. Porto Alegre: Zouk, 2019, pp. 137-54.

SIRVENT, Carlos (Coord.). Gramsci y la política. México D.F.: UNAM, 1980.

SIRVENT, Carlos. Gramsci y la politica. Gazeta de la UNAM, n 63, 7 set. 1978, p. 10. Disponí-vel em: http://acervo.gaceta. unam.mx/index.php/gum70/issue/view/1416/showToc.

SOARES, Rosemary Dore. Gramsci, o Estado e a escola. ljuí: Unijuí, 2000.

SRIVASTAVA, Neelan; BHATTACHARYA, Baidik (Eds.). The Postcolonial Gramsci. New York: Routledge, 2012.

TACATIC CÁCERES, Borki Ulianov. Aplicaciones del concepto de revolución de Antonio Gramsci a El Salvador. Tesi di laurea, Universidad Centroamericana “Jospé Simeon Cañas”, 1993.

TAPIA, Luis. La producción del conocimiento local: historia y política en la obra de René Zavaleta. La Paz: Muela del Diablo Editores, 2002. 
THOMAS, Peter D. Cramsci's Marxism: the "Philosophy of Praxis". MCNALLY, Mark (Ed.) Antonio Gramsci. London: Palgrave Macmillan, 2015, pp. 97-117.

THWAITES REY, Mabel; LOGIÚDICE, Edgardo; FERREYRA, Leandro. Gramsci mirando al sur: sobre la hegemonía en los 90. Buenos Aires: Kohen Asociados, 1994.

TRENTIN SILVEIRA, Rene. A Relação Professor-Aluno de uma Perspectiva Gramsciana. Educação e Realidade, v. 43, pp. 97- 114, 2018.

VACCA, Giuseppe. Modernidades alternativas. O século XX de Antonio Gramsci. Brasília: Fundação Astrojildo Pereira, 2016.

VACCA, Giuseppe. Vida e pensamento de Antonio Gramsci, 1926-1937. Brasília: Fundação Astrojildo Pereira, 2012.

VARESI, Gastón. Estudio introductorio. In: Gramsci, A. Hegemonía y lucha política en Gramsci. Buenos Aires: Luxemburg, 2015.

VIANNA, Luiz Werneck. A revolução Passiva. Iberismo e americanismo no Brasil. Rio de Janeiro: Revan, 2004. (1 ed. 1997).

VOLPI, Alessandro. Gli usi di Gramsci in Argentina: dal marxismo critico di "Pasado y Presente" al post-marxismo di Ernesto Laclau. Tesi di laurea in Storia della Filosofia, Università di Bologna, Bologna, 2019.

ZAVALETA MERCADO, René. Clases sociales y conocimiento. Cochabamba- La Paz: Los amigos del Pueblo, 1988.

ZAVALETA MERCADO, René. El estado em América Latina. Cochabamba-La Paz: Los amigos del Pueblo, 1990.

\section{Notas}

1 Versão atualizada do texto originalmente publicado na revista Materialismo Storico, Urbino, n. 2, p. 221-264, 2019. Tradução do italiano de Rodrigo Lima Ribeiro Gomes.

2 Professor do Departamento de Sociologia e Ciência Política na Universidade Federal de Santa Catarina (UFSC), Brasil. ORCID: http://orcid.org/0000-00017482-1416. E-mail: raul.ufsc@gmail.com

3 Naquela ocasião apresentei a comunicação // nodo latino-americano dell'egemonia: da "Pasado y Presente" al seminario di Morelia (1980). Per i quarant'anni di Los usos de Gramsci di Juan Carlos Portantiero, publicado posteriormente (junto a outros textos apresentados no mesmo evento) na revista Materialismo storico, $n^{\circ} 1 / 2017$ (vol. II). 
4 Um resultado preliminar dessas novas pesquisas se encontras em Burgos, 2019a.

5 Seminário Cramsci y la Política, ocorrido na Cidade do México, entre 5 e 9 de setembro de 1978, organizado pela Comisión Técnica de estudios y proyectos da UNAM, e coordenado por Carlos Sirvent. Participaram do evento: Maria Antonietta Macciocchi, Christine Buci-Glucksmann, Juan Carlos Portantiero e Giuseppe Vacca. Seminário Hegemonía y alternativas políticas en América Latina, ocorrido em Morelia, Michoacán, em fevereiro de 1980, coordenado por Julio Labastida Martín Del Campo, Instituto de Investigaciones Sociales de la Universidad Nacional Autónoma de México. Participaram vinte e sete pesquisadores latino-americanos e europeus. Seminário Los nuevos procesos sociales y la teoría política contemporánea. Instituto de Investigaciones Sociales, UNAM, Oaxaca, México, de 30 março a 05 de abril de 1981. Também neste seminário participaram vinte e sete pesquisadores latino-americanos e europeus.

6 Para uma melhor compreensão da vida e da obra de José Aricó, deve-se remeter ao trabalho de Crespo (2001) e Cortés (2015). Uma generosa coletânea de textos fundamentais encontra-se em Aricó (2018).

7 Kanoussi (2011, pp. 316-317), por exemplo, afirma: “Graças à experiência argentina, no México começou a estabelecer-se entre os estudiosos provenientes de vários países da América Latina, um forte entrelaçamento entre o estudo, a difusão da obra de Gramsci e a ação política, que provocou uma renovação do marxismo, em ruptura com a tradição soviética e seu dogmatismo, e se tornou a base para uma luta pela democracia".

8 De um ponto de vista que se poderia definir como "institucional", formaram-se associações gramscianas em diversos países, que estão favorecendo o encontro e a formação de pesquisadores, melhorando a nossa capacidade de identificar os principais desafios teórico-políticos. Hoje, já existem associações na Argentina (http://gramsciargentina.org/), no Brasil (http://igsbrasil.org/), no México (https://gramscimexico.org/) e na Colômbia (http://www.globalgramscisociety.com/), e outras estão em fase inicial de articulação, como são os casos de Bolívia, Paraguai, Chile e Equador.

9 Para maiores informações ver: Cortés e Burgos, 2019.

10 Mapa Bibliográfıco de Gramsci no Brasil, Universidade Federal Fluminense (UFF), Faculdade de Educação (FEUFF), Programa de Pós-Graduação em Educação (PPGE), Núcleo de Estudos e Pesquisas em Filosofia, Política e Educação (NuFiPE). Coordenador: Giovanni Semeraro, 2016 (http://igsbrasil.org/mapa-bibliografico-igs-brasil/). Na sua $3^{\circ}$ Edição, publicada em setembro de 2019, o levantamento registrava um total de 1.704 títulos, classificados da seguinte maneira: I) Livros e coletâneas publicadas, com capítulos integrais e/ou parciais sobre Gramsci: 142; II) Capítulos de livros: 329; III) Artigos ou ensaios publicados: 584; IV) Teses (223) e dissertações (426), num total de 649 títulos. 
11 Zavaleta Mercado propõe o conceito de formação social abigarrada (e mesmo de sociedade abigarrada) para dar conta, sinteticamente, de sociedades altamente heterogêneas como a boliviana, nas quais as formas sociais originarias, o domínio colonial e o desenvolvimento capitalista articulam-se de modos hipercomplexos. A ideia de Estado aparente, por sua vez, é utilizada para designar as formas de Estado nas quais essa instância social não consegue incluir na sua representação a totalidade (territorial, social, cultural, formas de organização política) dessas sociedades heterogêneas, representando apenas os setores privilegiados.

12 Um esforço acadêmico ulterior para pensar a continuidade do processo em termos gramscianos se encontra em outra monografia defendida na mesma universidade: o trabalho de Guillermo Eduardo Aguirre Melara, La nueva hegemonía política y cultural en El Salvador de posguerra. Universidad Centroamericana “José Simeon Cañas”, San Salvador, 1998.

13 Uma síntese do discurso de Chávez se encontra no endereço: https://www.youtube. com/watch?v=xxnWoR61z30. O discurso completo se encontra no endereço: https://www.youtube.com/watch?time_continue=6\&v= NBUChbbt-HO\&feature= emb_logo.

14 A expressão Abya Yala, que, na língua do povo Kuna significa "terra madura", "terra vivente" ou "terra florida", foi usado como autodesignação pelos povos do continente, em contraposição ao termo "América". Ainda que as diversas populações indígenas que habitaram o continente tenham dado nomes próprios as regiões que ocupavam (Tawantinsuyo, Anauhuac, Pindorama etc.), a expressão Abya Yala foi crescentemente utilizada pelas populações indígenas do continente, para constituir um sentido de unidade e pertencimento. A primeira vez que o termo foi utilizado explicitamente com esse sentido político foi na ocasião da II Cúpula dos Povos e Nacionalidades Indígenas de Abya Yala, ocorrida em Quito em 2004. Em 2007, entretanto, na III Cúpula dos Povos e Nacionalidades Indígenas de Abya Yala, ocorrida em Iximche, Guatemala, decidiu também instituir uma coordenação continental das nacionalidades e dos povos indígenas de Abya Yala. Cf. Carlos Walter Porto-Gonçalves, Abya Yala, em Enciclopédia latino-americana (http://latino-americana.wiki.br/ verbetes/a/abya-yala).

15 Uma síntese documentada - contendo também contra-argumentos - dos genocídios na América e na África a partir das invasões europeias se encontram no artigo da Wikipedia, "Catástrofe demográfica en América tras la llegada de los europeos". Quando os europeus deram início à invasão do território posteriormente chamado de América, a população máxima estimada na Europa era de 70 milhões, diante de 110 milhões de nativos americanos. Desses, 95\% morrem nos primeiros 130 anos posteriores à invasão, durante aquele que é considerado o maior genocídio da história. Para substituir como trabalhadores o grande número de indígenas mortos durante o século XVI, a partir do século 
XVII os europeus capturaram cerca de 60 milhões de africanos ao sul do Saara. Desses, cerca de 12 milhões chegaram vivos na América, onde foram reduzidos à escravidão (https://w.wiki/GER).

16 Ocupei-me desse tema em Burgos (2019b).

17 Tomo de Kanoussi (2011, p. 353) o desafio de "compreender como o conceito de tradutibilidade (derivado daquele de metáfora), de instrumento ou técnica de pensamento, alcança a dimensão de uma teoria". Além de Kanoussi, entre os autores que contribuíram na compreensão da teoria da tradutibilidade, gostaria de mencionar Frosini $(2003,2016,2019)$ e Lacorte $(2010,2012,2014)$.

18 Esta relação é evidente também em dois autores latino-americanos fundamentais: Paulo Freire e José Aricó. A propósito de Freire, Chabalgoity (2018, p. 78) usa a expressão "andarilhagem filosófica freiriana", em referência ao modo pelo qual o autor absorve e reelabora tradições filosóficas diversas para formular seu projeto teórico-político: "na Pedagogia do Oprimido encontramos as vozes de Guevara, Mao Tse-Tung e Marx [...]. A maturidade do período, por sua vez, é vislumbrada em Ação Cultural para a liberdade e outros escritos. Neste livro, a aproximação gramsciana é decisiva". Do pensamento de Aricó, poder-se-ia dizer algo similar. Por exemplo, Cortés (2015, p. 40) põe em relevo a seguinte característica: "O marxismo de Aricó torna-se cada vez mais complexo, por meio da constante incorporação de fontes durante todos seus anos de atividade como intelectual e editor. Portanto, resulta difícil encontrar um adjetivo que descreva de modo definitivo, completo e específico à sua inscrição multiforme na tradição: leninista, gramsciano, althusseriano, maoísta, mariateguiano, latino-americanista, conseIhista, obreirista, social-democrático, desencantado, crítico, aberto, benjaminiano". Nesse sentido, de acordo com a hipótese principal do estudo de Cortés: “O marxismo de Aricó é, sobretudo, o desdobramento de uma imensa estratégia de tradução que procura introduzir no debate latino-americano diversos problemas, textos, discussões e tradições..." (CORTÉS, 2015, p. 40).

19 Nesse sentido, considero utilíssima a definição de Williams (1980, pp. 131-32): "A hegemonia constitui um corpus integral de práticas e expectativas em relação à totalidade da vida: nossos sentidos e as doses de energia, nossas percepções acerca de nós mesmos e do nosso mundo. É um sistema vívido de significados e valores - fundamentais e constitutivos - que, na medida em que os experimentamos como práticas, parecem confirmar-se reciprocamente. Portanto, é um senso de realidade para a maior parte das pessoas em uma sociedade [...] Ou seja, num sentido mais forte, é uma cultura, mas uma cultura que também deve ser considerada como a dominação e a subordinação vivenciadas por classes particulares".

20 Deixo de fora desta lista a crítica da equação "marxismo = capitalismo", que mereceria uma discussão mais alongada. Apesar disso, considero interessante mencionar a observação de Chabalgoity (2018, pp. 80-81) sobre a presença 
de uma síntese - uma "mistura explosiva", afirma o autor - entre decolonialismo e marxismo no pensamento de Paulo Freire, no qual, sobretudo na Pedagogia do Oprimido, podemos encontrar "uma dialética constante" entre essas duas formas de pensamento.

\section{Cf. CENTRO DE ESTUDIOS GERMINAL (2019).}

22 Argumentos sólidos sobre a estreita relação Zavaleta-Cramsci se encontram em Ouviña, 2016.

23 Os comentários de Liguori e Vacca foram transcritos do vídeo da conferência, disponivel no endereço: https://www.youtube.com/watch?v=ImcwJGaUA64, no intervalo de tempo entre 17:58:35 e 18:16:38.

24 "A Edizione nazionale degli scritti di Antonio Cramsci, posta sob o Alto Patronato del Presidente della Repubblica em 1990, foi instituída pelo Ministero per i Beni culturali e ambientali, a partir de um Decreto Ministerial de 20 de dezembro de 1996. Nomeada a comissão científica destinada a estabelecer o plano da obra e a realizá-la, em 1998, foi aprovada uma divisão em seções que assumiram as seguintes denominações: Scritti 1910-1926; Quaderni del carcere 1929-1935; Epistolario 1906-1937. O editor da obra é o Istituto della Enciclopedia italiana". Da página da internet da Fundação Gramsci. Acessivel no endereço: https://www. fondazionegramsci.org/edizione-nazionale-scritti-antonio-gramsci/

25 Em termos históricos: Rapone (2019), Vacca (2012), D’Orsi (2017); em termos filosóficos: Frosini (2010), Cospito (2011); em termos linguísticos: Schirru (2008), Carlucci (2013) etc.

26 Uma excelente discussão sobre este debate, desde uma leitura política que valoriza altamente a produção filológica, procurando se servir dela em função de projetos políticos estratégicos, encontra-se em Balsa (2019b). 


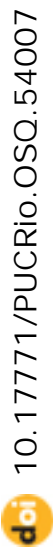

